\title{
Analysis of the critical heat flux of subcooled flow boiling in microgravity
}

\author{
Bin Liu ${ }^{\mathrm{a}}$, Bo Yuan ${ }^{\mathrm{a}}$, Jie Zhou ${ }^{\mathrm{a}}$, Jianfu Zhao ${ }^{\mathrm{b}, \mathrm{c}}$, Paolo Di Marco ${ }^{\mathrm{d}}$, Yonghai Zhanga,*, Jinjia Wei ${ }^{\mathrm{a}, \mathrm{e}, *}$, \\ Yang Yang ${ }^{\mathrm{f}}$
}

a School of Chemical Engineering and Technology, Xi'an Jiaotong University, Xi'an 710049, China

${ }^{\mathrm{b}}$ CAS Key Laboratory of Microgravity, Institute of Mechanics, Chinese Academy of Sciences, Beijing 100190, China

${ }^{c}$ School of Engineering Science, University of Chinese Academy of Sciences, 19A Yuquan Rd, Beijing 100049, China

${ }^{\mathrm{d}}$ Department of Energy, Systems, Constructions and Territory Engineering, University of Pisa, Pisa 56122, Italy

${ }^{\text {e }}$ State Key Laboratory of Multiphase Flow in Power Engineering, Xi'an Jiaotong University, Xi'an 710049, China

${ }^{\mathrm{f}}$ Technology and Engineering Center for Space Utilization, Chinese Academy of Sciences, Beijing 100094, China

\section{A R T I C L E I N F O}

\section{Keywords:}

Flow boiling

Critical heat flux

Microgravity

Prediction

Bubble behavior

\begin{abstract}
A B S T R A C T
There is a significant decrease in flow boiling CHF when the inertial force of the fluid is not large enough in microgravity, but this tendency decreases with the increase of the inertial force. In the present study, the critical heat flux (CHF) of subcooled flow boiling at different gravity levels on smooth silicon surfaces was investigated. The working fluid is FC-72, with the subcooling of $15 \mathrm{~K}$. The flow boiling heat transfer characteristics, including the CHF, wall temperatures and bubble behavior were studied. The effects of the heater length, channel height and flow velocity on the CHF were studied. It was found that the CHF increases with the increase of the channel height and flow velocity, but decreases with the increase of the heater length. A similar tendency was found for the ratio of the CHF in microgravity to that in normal gravity $\left(q_{\mathrm{CHF}-\mu \mathrm{g}} / q_{\mathrm{CHF}-1 \mathrm{~g}}\right)$. The relation of the flow velocity, heater length, channel geometrical parameters, and $q_{\mathrm{CHF}-\mu \mathrm{g}} / q_{\mathrm{CHF}-1 \mathrm{~g}}$ was studied by the dimensionless analysis. Finally, a correlation for the prediction of $q_{\mathrm{CHF}-\mu \mathrm{g}} / q_{\mathrm{CHF}-1 \mathrm{~g}}$ was developed based on the dimensionless analysis and the prediction results agree quite well with the experimental data within $\pm 10 \%$.
\end{abstract}

\section{Introduction}

Flow boiling is widely used in thermal management systems [1], energy power system [2], and microelectronic device heat dissipation [3]. It is well known that the flow boiling heat transfer performance in microgravity is different from that in earth gravity due to the absence of buoyancy [4]. The absence of the gravity severely weakens the buoyancy that helps the bubbles departure, causes more serious lateral bubble coalescence as well as premature heat transfer deterioration, and resulting in a decrease in CHF [5-9]. Therefore, it is of great significance to investigate the flow boiling heat transfer in microgravity for the thermal management and microelectronic device heat dissipation for space equipment. However, only a few experiments on flow boiling in microgravity have been reported [5-9] due to the difficulty in obtaining microgravity conditions and the complexity of the flow boiling experimental system.

Flow boiling in microgravity has been studied for more than 40 years. The main attention of the investigation on flow boiling in microgravity has been paid on the flow boiling heat transfer coefficient [10-13], bubble dynamics [14-16], the flow pattern of vapour/ gas-liquid flow [17-22], and critical heat flux [17,23-29]. CHF is a crucial parameter in flow boiling which determines the limit of nucleate boiling. Therefore, it is very important for the safety of the thermal management system and electronic devices.

Ohta [17] first measured the flow boiling CHF at high inlet quality in microgravity, but he only obtained one CHF point in microgravity ( $q_{\mathrm{CHF}, \mu \mathrm{g}}=3-4 \mathrm{~W} / \mathrm{cm}^{2}$ using R113 as working fluid) and he did not report the CHF value in normal gravity. Therefore, the effects of gravity on CHF is not clear. Using $2.1 \mathrm{~s}$ drop tower, Ma and Chung [23] measured the subcooled flow boiling CHF in microgravity around a platinum wire, they found that the CHF in microgravity tends to decline significantly compared to that in normal gravity under corresponding conditions. However, the gap between the CHF in microgravity and that in normal gravity was narrowed with the increase of flow velocity.

The longer the duration of microgravity, the more beneficial it is to obtain more accurate experimental data. Using parabolic flights, Zhang et al [24] and Konishi et al. [25,26] found that the vapor patches grew in length and formed a wavy vapor layer that propagated along the wall, permitting liquid access only in the wave troughs as CHF was approached, and the CHF was triggered by separation of the

\footnotetext{
* Corresponding authors.

E-mail addresses: zyh002@mail.xjtu.edu.cn (Y. Zhang), jjwei@mail.xjtu.edu.cn (J. Wei).
} 


$\begin{array}{ll}\text { Nomenclature } \\ \text { Ch } & \text { channel number } \\ \text { CHF } & \text { critical heat flux }\left(\mathrm{W} / \mathrm{cm}^{2}\right) \\ D_{\mathrm{h}} & \text { hydraulic diameter }(\mathrm{mm}) \\ E o & \text { Eötvös number } \\ g & \text { gravitational acceleration }\left(\mathrm{m} / \mathrm{s}^{2}\right) \\ 1 \mathrm{~g} & \text { earth gravity level }\left(\mathrm{m} / \mathrm{s}^{2}\right) \\ H & \text { channel height }(\mathrm{mm}) \\ I & \text { heating current }(\mathrm{A}) \\ K & \text { CHF } \mu \text { / } / \text { CHF } 1 \mathrm{~g} \text { of pool boiling } \\ L & \text { heater length (mm) } \\ L_{\mathrm{c}} & \text { capillary length (mm) } \\ p_{\mathrm{h}} & \text { heated perimeter }(\mathrm{mm}) \\ p_{\mathrm{w}} & \text { wetted perimeter }(\mathrm{mm}) \\ q & \text { heat flux }\left(\mathrm{W} / \mathrm{cm}^{2}\right) \\ q_{\mathrm{con}} & \text { conductive heat flux }\left(\mathrm{W} / \mathrm{cm}^{2}\right) \\ S f & \text { surface number } \\ t & \text { time (s) }\end{array}$

$T_{1}, T_{2}, T_{3}, T_{4}$ wall temperatures $\left({ }^{\circ} \mathrm{C}\right)$

$T_{\mathrm{a}} \quad$ average wall temperature $\left({ }^{\circ} \mathrm{C}\right)$

$T_{\mathrm{f}} \quad$ liquid temperature $\left({ }^{\circ} \mathrm{C}\right)$

$T_{\text {sat }} \quad$ saturation temperature $\left({ }^{\circ} \mathrm{C}\right)$

$U \quad$ heating voltage (V)

$V \quad$ inlet liquid velocities $(\mathrm{m} / \mathrm{s})$

$W \quad$ width of heater (mm)

We Weber number

Greek symbol

$\begin{array}{ll}\rho_{\mathrm{g}} & \text { vapor density }\left(\mathrm{kg} / \mathrm{m}^{3}\right) \\ \rho_{\mathrm{l}} & \text { liquid density }\left(\mathrm{kg} / \mathrm{m}^{3}\right) \\ \sigma & \text { surface tension }(\mathrm{N} / \mathrm{m}) \\ \mu g & \text { gravitational acceleration in microgravity }\left(\mathrm{m} / \mathrm{s}^{2}\right) \\ \Delta q_{\mathrm{V}} & \text { uncertainty of heat flux due to fluctuation of volume flow } \\ & \text { rate }\left(\mathrm{W} / \mathrm{cm}^{2}\right) \\ \Delta T_{\text {sat }} & \text { wall superheat }=T_{\mathrm{w}}-T_{\mathrm{sat}}(\mathrm{K}) \\ \Delta T_{\text {sub }} & \text { fluid subcooling }=T_{\text {sat }}-T_{\mathrm{b}}(\mathrm{K})\end{array}$

liquid-vapor interface from the wall due to intense vapor effusion in the troughs. In addition, Zhang et al. [24] tested the flow boiling CHF in a single-heated rectangular channel with different inlet liquid velocities under different gravity conditions. They found that the $q_{\mathrm{CHF}-\mu \mathrm{g}} / q_{\mathrm{CHF}-1 \mathrm{~g}}$ increases with the increase of inlet velocity, and the effects of gravity levels can be neglected ( $\left.q_{\mathrm{CHF}-\mu \mathrm{g}} / q_{\mathrm{CHF}-1 \mathrm{~g}}>0.9\right)$ when the inlet velocity is greater than the threshold value $(1.5 \mathrm{~m} / \mathrm{s})$. While Konishi et al. $[25,26]$ found that the flow boiling heat transfer performance in a two opposite heated rectangular channel is better than that in a single-sided heated rectangular channel at the same conditions due to the faster fluid motion. For the flow boiling in a two opposite heated rectangular channel, the $q_{\mathrm{CHF}-\mu \mathrm{g}} / q_{\mathrm{CHF}-1 \mathrm{~g}}$ is larger than that in a single-sided heated rectangular channel at the same inlet velocity. Zhang et al. [27,28] tested the subcooled flow boiling CHF of smooth surface and micro-pinfinned surface in a single-side heated rectangular channel in microgravity via $3.5 \mathrm{~s}$ drop tower, and they found that except for the flow velocity, the geometric parameters of the channel, length of the heater and surface modification also show significant influence on $q_{\mathrm{CHF}-\mu \mathrm{g}}$ / $q_{\mathrm{CHF}-1 \mathrm{~g}}$. Liu et al. [29] proposed a criterion for approximating the flow boiling CHF in microgravity by ground tests and proved it by drop tower experiments and a modified heat flux partitioning model. It was suggested that the CHFs in microgravity can be obtained conveniently by the ground tests according to this criterion.

As mentioned above, it is difficult to measure CHF in microgravity flow boiling. Therefore, it will be very convenient if we can obtain the flow boiling CHF in microgravity through the empirical correlations, prediction models or ground tests. $q_{\mathrm{CHF}-\mu \mathrm{g}} / q_{\mathrm{CHF}-1 \mathrm{~g}}$ is a very important parameter for flow boiling heat transfer in microgravity. If the factors that affect $q_{\mathrm{CHF}-\mu \mathrm{g}} / q_{\mathrm{CHF}-1 \mathrm{~g}}$ and the corresponding influencing laws can be obtained, the CHF in microgravity can be easily obtained by the ground tests obtained under the corresponding working conditions. Zhang et al. [28] developed an empirical correlation for $q_{\mathrm{CHF}-\mu \mathrm{g}} / q_{\mathrm{CHF}-1 \mathrm{~g}}$ prediction. But due to the lack of experimental data, the database of Zhang et al. [28] is very limited and some factors that affect $q_{\mathrm{CHF}-\mu \mathrm{g}}$ / $q_{\mathrm{CHF}-1 \mathrm{~g}}$ did not be analyzed comprehensively.

In summary, there are three shortcomings in the CHF of flow boiling in microgravity in literature: 1) only a few experimental data of flow boiling CHF in microgravity has been reported; 2) the research on the effects of the experimental conditions on flow boiling CHF in microgravity is still very scarce; and 3) no widely accepted empirical correlation for $q_{\mathrm{CHF}-\mu \mathrm{g}} / q_{\mathrm{CHF}-1 \mathrm{~g}}$ prediction has been proposed. Therefore, obtaining more basic experimental data, in-depth research on the influence of $\mathrm{CHF}$ and developing a widely accepted empirical correlation are very important for flow boiling research in microgravity.
In the present study, the subcooled flow boiling CHF was analyzed based on the drop tower experimental results in our previous study [29]. A comprehensive investigation on the effects of the flow velocity, heater length and channel size on of $q_{\mathrm{CHF}-\mu \mathrm{g}} / q_{\mathrm{CHF}-1 \mathrm{~g}}$ based on the experimental results reported in our previous study and other literature was conducted. Furthermore, a correlation for the prediction of $q_{\mathrm{CHF}-\mu \mathrm{g}} /$ $q_{\mathrm{CHF}-1 \mathrm{~g}}$ was developed based on the dimensionless analysis.

\section{Experimental method}

A method for approximating the CHF of subcooled flow boiling in microgravity by ground tests was proposed in our previous study. The method suggests that the flow boiling CHF in microgravity can be approximated by using the range of the $\mathrm{CHF}$ under the heater inclination of $315^{\circ}$ and the CHF under the heater inclination of $135^{\circ}$ in normal gravity under the corresponding conditions [29]. Based on this approximate method, five cases of drop tower tests were conducted. Firstly, considering the effects of the heater length, flow velocity and channel size, the experimental conditions for these five cased were determined. Next, the CHFs under the heater inclination of $315^{\circ}$ and $135^{\circ}$ were measured on the ground. Then, the experimental matrix for drop tower tests was established based on the results of the ground tests. Finally, the drop tower tests were conducted based on the experimental matrix.

The subcooled flow boiling experiments in microgravity were conducted by the drop tower in NML of CAS, Beijing [30]. The tall of the drop tower is $116 \mathrm{~m}$ with about $61 \mathrm{~m}$ free fall height. The gravity level in microgravity $(\mu g)$ is approximately $10^{-2} g$, where $g$ is gravitational acceleration on the ground. The duration of the microgravity environment in each drop tower test is $3.5 \mathrm{~s}$.

The experimental setup is schematically shown in Fig. 1. A micro vortex pump was used to pump liquid to the pipeline. The flow velocities $(V)$, which were adjusted by a potentiometer and a valve, were 0.5 and $1.0 \mathrm{~m} / \mathrm{s}$ for the drop tower tests. The flow direction is horizontal and the outlet pressure is $1 \mathrm{~atm}$. The pressure drop between the inlet and outlet of the test section has been measured by a differential pressure transmitter in our previous study. It was found that the maximum pressure difference between the inlet and outlet is less than $1.4 \mathrm{kPa}$ both under normal gravity and microgravity [28]. Therefore, the pressure drop between the inlet and outlet was neglected and test pressure can be approximated to $1 \mathrm{~atm}$ in the present study. To investigate the effects of the channel geometrical parameters on the CHF, two rectangular channels with a cross-section of $12 \times 3 \mathrm{~mm}^{2}$ and $12 \times 5 \mathrm{~mm}^{2}$ (width $\times$ height) were used. The heating surface was 


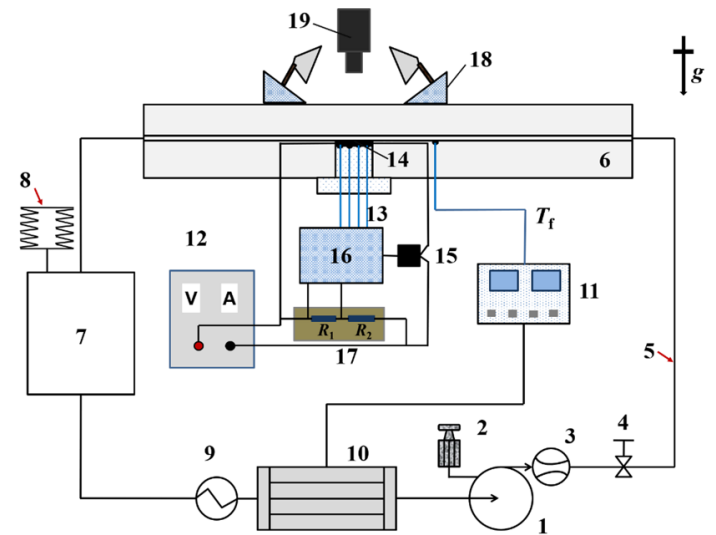

1. Pump 2. Potentiometer 3. Turbine flowmeter 4. Valve 5. Pipeline 6. Test section 7. Tank 8. Rubber bag 9. Auxiliary heater 10. Condenser 11. Temperature controller 12. DC power 13. Thermocouples 14. Heated surface 15. Hall sensor 16. Data acquisition 17. Standard resistance 18. Light source 19. High speed camera

Fig. 1. Schematic diagram of the experimental setup.

horizontal upward placed in the channel and the camera was facing the heating surface. An auxiliary heater was installed in the tank for preheating the liquid to $41{ }^{\circ} \mathrm{C}$. A rubber bag was used to maintain the pressure at $1 \mathrm{~atm}$. The silicon surface was packaged in the plexiglass base by the heat insulation glue and then inserted into the rectangular channel, as shown in Fig. 2.

The smooth silicon surface was Joule heated by a DC power source. To achieve Joule heating, the N-doped silicon chips with a thickness of
$0.5 \mathrm{~mm}$ and a width of $10 \mathrm{~mm}$ were used as the heating surfaces. Two copper wires were bond on the two opposite sides of the silicon surface by ultrasonic welding, and the contact resistance between the silicon surface and copper wires can be neglected, as shown in Fig. 2(a). To decrease the heat loss, the gap between the heater and the plexiglass base was filled with thermal insulation glue, as shown in Fig. 2(b). As better detailed in the following, the heat transfer can be considered only taking place effectively on the top side of the heater. To study the influence of the heater length on the CHF at different gravity levels, three types of heaters with the lengths of 10,20 and $40 \mathrm{~mm}$ were used in the present study. The thermocouples were pasted on the bottom side of the heating surface with thermal conductive adhesive with an interval distance of $10 \mathrm{~mm}$, as shown in Fig. 2(c).

The working fluid is FC-72, with the subcooling $\left(\Delta T_{\text {sub }}\right)$ of $15 \pm 0.5 \mathrm{~K}$. The working fluid was not degassed because the noncondensable gas only has a significant influence on boiling performance at the beginning of nucleate boiling, while for the CHF that the present study focuses on, the effects of non-condensable gas can be negligible [31-32]. Before the free fall process, the auxiliary heater was turned on through the remote control system to heat the fluid temperature to 41 ${ }^{\circ} \mathrm{C}$. And then the fluid temperature was kept at $41 \pm 0.5^{\circ} \mathrm{C}$ by a PID temperature control system. To achieve the stable flow boiling state, the surface was heated for at least 2.5 mins before the drop capsule releases until the wall temperature change within $30 \mathrm{~s}$ is less than $0.2 \mathrm{~K}$. A constant voltage was applied to the heating surface during the experiment. When CHF occurs, the wall temperature increases sharply, and the resistivity of the silicon chip increases with the increasing wall temperature, which leads to a decrease in the heating current and heat flux. In addition, these changes mentioned above is irreversible during the free-falling and the rising rate of the wall temperature is higher than (a)

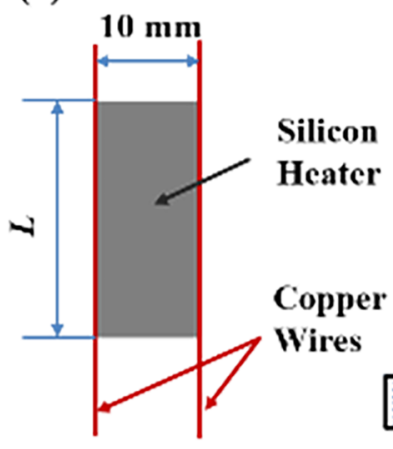

(b)

\section{Chip Unit \\ IIeat Insulation Glue}


$10 \mathrm{~K} / \mathrm{s}$. Therefore, the CHF can be classified by the tendency of wall temperature, heating current and boiling phenomenon. A high-speed camera that was fixed on the top of the heating surface at $1000 \mathrm{fps}$ with a resolution of $256 \times 1280$ was used to recording the bubble behavior during the drop tower test.

Considering the influence of the heater length, flow velocity and channel height on the subcooled flow boiling CHF, five cases of drop tower experiments named L40V05H3, L20V05H3, L10V05H3, L40V10H3, and L40V05H5, respectively, were conducted. Only the region approximating the $\mathrm{CHF}$ in microgravity was investigated. Before the drop tower test, the flow boiling curves and the CHFs were tested on the ground. Then, the heat flux $(q)$ for each drop tower test was decided according to the criterion for approximating flow boiling heat transfer by ground tests [29]. The CHF in microgravity is smaller than that in normal gravity due to the lack of gravity. Therefore, the set value of heat flux for the drop tower test is smaller than that in normal gravity. For each case, two drop tower tests with different heat fluxes were conducted to obtain the region that contains the CHF value in microgravity. The experimental conditions were listed in Table 1. Due to the limit of the experimental resource, only 9 times of drop tower tests were conducted in the present study, and each test was only conducted once.

The fluid temperature was measured by a platinum resistance thermometer with the uncertainty of $0.23 \mathrm{~K}$. T-type thermocouples (OMEGA TT-T36-SLE) with a diameter of $0.127 \mathrm{~mm}$ were used to measure the wall temperatures. The uncertainties of wall temperature are less than $0.36 \mathrm{~K}$ and $0.68 \mathrm{~K}$ in the steady-state and unsteady state, respectively. The signals of the wall temperatures $\left(T_{1}, T_{2}, T_{3}, T_{4}\right)$, flow velocity $(V)$, gravity acceleration $(g)$, heating voltage $(U)$ and the heating current $(I)$ recorded by the data acquisition. The heat flux of the boiling surface (based on the measured heat flux minus the heat loss, $\varepsilon$ ) can be calculated as [33]

$q=\frac{U \cdot I(1-\varepsilon)}{L \cdot W}$

where $L, W$ and $\varepsilon$ represent the length, width of the heater, and the ratio of heat losses, respectively. The thickness of the thermal insulation glue with a heat conductivity coefficient of $0.2 \mathrm{~W} / \mathrm{m} \mathrm{K}$ in the gap between the heater and the plexiglass base is $2.5 \mathrm{~mm}$. According to the onedimensional Fourier law, the heat loss through the substrate of the heating surface is estimated to be less than $1.7 \%$ ( $240 \mathrm{~V} 05 \mathrm{H} 3$ at $q=19.3 \mathrm{~W} / \mathrm{cm}^{2}$ ).

The uncertainty of the measured heat flux can be calculated as

$\frac{\Delta q}{q}=\sqrt{\left(\frac{\Delta U}{U}\right)^{2}+\left(\frac{\Delta I}{I}\right)^{2}+\left(\frac{\Delta L}{L}\right)^{2}+\left(\frac{\Delta W}{W}\right)^{2}}$

In the present study, only the data approaching the CHFs were recorded (the minimum heat flux is $18.2 \mathrm{~W} / \mathrm{cm}^{2}$ ). The measurement uncertainties for $\Delta U / U, \Delta I / I, \Delta L / L$, and $\Delta W / W$ are $0.1 \%, 0.014 \%, 0.5 \%$ and $0.5 \%$, respectively. Thereby the uncertainty of the measured heat flux is $0.7 \%$. The heat conduction loss through the substrate of the heating surface $\left(\Delta q_{\mathrm{con}} / q\right)$ and the effects of the fluctuation of flow velocity on the heat flux $\left(\Delta q_{\mathrm{V}} / q\right)$ should also be considered in the present study. The maximum uncertainty of the heat flux caused by the fluctuation of the volume flow rate $\Delta q_{\mathrm{v}} / q$ is approximately $1.1 \%$. Therefore, the uncertainty of total heat flux is approximately $1.3 \%$. More details on the experimental method can be found in our previous article [27-29].

\section{Results}

The flow boiling heat transfer performance with the condition of $L=40 \mathrm{~mm}, V=0.5 \mathrm{~m} / \mathrm{s}$ and $H=3 \mathrm{~mm}$ was been reported in our previous study [27]. However, the CHF of the smooth surface in microgravity under this condition $\left(18.2-21.3 \mathrm{~W} / \mathrm{cm}^{2}\right)$ is not precise. To obtain a more precise $\mathrm{CHF}$ value for this condition, one drop tower test with a heat flux $(q)$ of $19.3 \mathrm{~W} / \mathrm{cm}^{2}$ was conducted in the present study. The validation of the experimental setup has been reported in our previous study by comparing the measured boiling curves with those reported in publications [27]. Therefore, we only compared our experiment results under the condition of $L=40 \mathrm{~mm}, V=0.5 \mathrm{~m} / \mathrm{s}$, and $H=3 \mathrm{~mm}$ with our previous study, as illustrated in Fig. 3. It can be found that these two boiling curves are very close to each other. Therefore, the experimental results in this study are reliable, and the results in Ref. [27] under this condition can also be used in the present study.

\subsection{Effects of the heater length, flow velocity and channel height on the flow boiling $\mathrm{CHF}$}

The comparison of the wall temperatures, heating voltage, heating current, and flow velocity at different gravity levels for L40V05H3 is shown in Fig. 4, where $t>0$ means the flow boiling in the stage of microgravity while $t<0$ represents the flow boiling in the stage of normal gravity. Note that at the end of the free fall process, there is a deceleration device at the bottom of the tower to avoid the damage of the experimental device. During the deceleration process, the experimental device will continue to undergo large up and down vibrations, so the gravity acceleration curve shows an obvious oscillation process when $t>3.5 \mathrm{~s}$.

As shown in Fig. 4, the wall temperatures and heating current are found to remain steady under different gravity levels at $q=18.2 \mathrm{~W} /$ $\mathrm{cm}^{2}[27,29]$. It is very important to ensure that the boiling can be reached to the stable-state within $3.5 \mathrm{~s}$. Iceri et al. [33] carried out the flow boiling experiments in microgravity by parabolic flight. They found that the wall temperatures increase immediately after entering microgravity and then reach a stable state within $10 \mathrm{~s}$. They also found that the increment in wall temperatures due to the decrease of gravity level decreases with the increase of mass velocity. However, the flow velocity (or mass velocity) in this study is much higher than that in Ref. [33] $\left(816 \mathrm{~kg} / \mathrm{m}^{2} \mathrm{~s}\right.$ at $V=0.5 \mathrm{~m} / \mathrm{s}$ and $1632 \mathrm{~kg} / \mathrm{m}^{2} \mathrm{~s}$ at $\left.V=1.0 \mathrm{~m} / \mathrm{s}\right)$ and the stable flow boiling has been reached before entering the microgravity environment. Therefore, the increase of wall temperatures at the lower heat flux of each case is not significant after entering microgravity in the present study. The maximum temperature increase, which was observed from L20V05H3 at $q=21.0 \mathrm{~W} / \mathrm{cm}^{2}$, is only $1.5^{\circ} \mathrm{C}$ after entering microgravity (Fig. A1 (a)). In this case, we also found that the wall temperatures increase immediately after entering microgravity, but they reach a stable state in a very short time (within $1 \mathrm{~s}$ ). This phenomenon is similar to that reported in Ref. [33]. The evolution of wall temperature after entering microgravity was also verified through a simple simulation of transient thermal conductivity by commercial software Comsol 5.5 (please see Appendix B). Therefore, it can be considered that the boiling states for the lower heat flux of all the 5 cases have reached the steady-state during the drop tower experiments.

In addition, it can be found in Fig. 4 that the flow velocities are

Table 1

The experimental conditions and results on the ground.

\begin{tabular}{llllll}
\hline Case number & $L(\mathrm{~mm})$ & $V(\mathrm{~m} / \mathrm{s})$ & $H(\mathrm{~mm})$ & $q\left(\mathrm{~W} / \mathrm{cm}^{2}\right)$ & $q / q_{\mathrm{CHF}-1 g}$ \\
\hline \multirow{2}{*}{ L40V05H3 } & 40 & 0.5 & 3 & $18.2[27]$ & $77.8 \%$ \\
& 40 & 0.5 & 3 & 19.3 & $83.9 \%$ \\
L20V05H3 & 20 & 0.5 & 3 & 20.7 & $85.9 \%$ \\
& 20 & 0.5 & 3 & 22.5 & $93.4 \%$ \\
L10V05H3 & 10 & 0.5 & 3 & 23.9 & $88.5 \%$ \\
& 10 & 0.5 & 3 & 25.6 & $94.8 \%$ \\
L40V10H3 & 40 & 1.0 & 3 & 23.3 & $87.9 \%$ \\
& 40 & 1.0 & 3 & 24.3 & $91.7 \%$ \\
L40V05H5 & 40 & 0.5 & 5 & 19.8 & $81.1 \%$ \\
& 40 & 0.5 & 5 & 21.2 & $86.9 \%$ \\
\hline
\end{tabular}




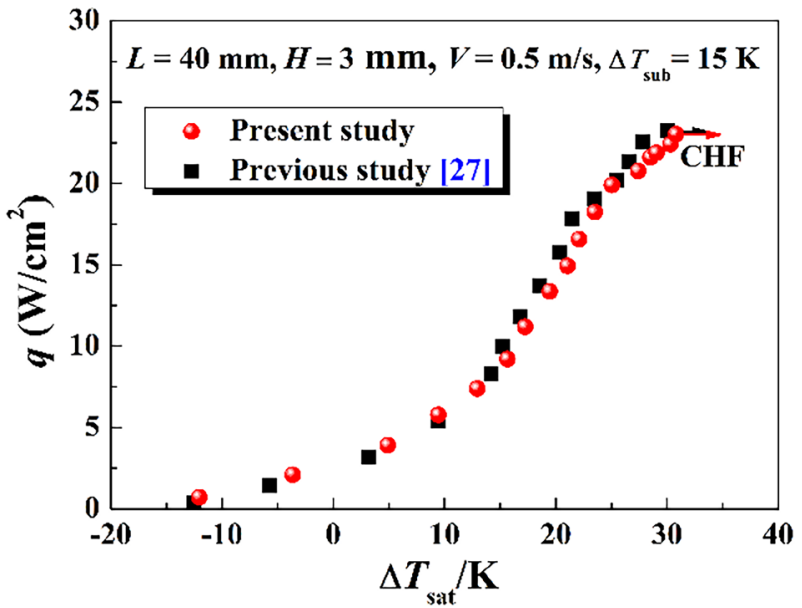

Fig. 3. Comparison of boiling curves in the present study and previous study.

maintained stable whatever the flow boiling state and gravity level is. Therefore, the influence of flow boiling state and gravity level on flow velocity can be neglected in the present study.

For the higher heat flux of each case, for example, L40V05H3 at $q=19.3 \mathrm{~W} / \mathrm{cm}^{2}$, the wall temperatures increase slowly at $0-0.5 \mathrm{~s}$ and then increases dramatically, accompanying the sharp decrease in heating current after $t=0.5 \mathrm{~s}$. This phenomenon indicates that the CHF reached under microgravity under this condition.

The comparison of bubble behavior at different gravity levels for this case is shown in Fig. 5. No remarkable distinction is observed in the bubble behavior between the microgravity condition and the normal condition at $q=18.2 \mathrm{~W} / \mathrm{cm}^{2}$, except that the bubbles at the downstream of the heating surface in microgravity are slightly larger than that in normal gravity. While at $q=19.3 \mathrm{~W} / \mathrm{cm}^{2}$, a very rapid transition from nucleate boiling to film boiling can be observed. Therefore, according to the comparison of Figs. 4 and 5, it can be inferred that the CHF does not occur at $q=18.2 \mathrm{~W} / \mathrm{cm}^{2}$ in microgravity while the CHF has occurred at $q=19.3 \mathrm{~W} / \mathrm{cm}^{2}$. Then, the CHF in microgravity for this case can be inferred to be between $18.2 \mathrm{~W} / \mathrm{cm}^{2}$ and $19.3 \mathrm{~W} / \mathrm{cm}^{2}$. Similarly, the CHFs in microgravity for L20V05H3 and L10V05H3 can be inferred in the ranges of $20.7-22.5 \mathrm{~W} / \mathrm{cm}^{2}$ and $23.9-25.6 \mathrm{~W} / \mathrm{cm}^{2}$, respectively (See Appendix A).

The maximum ranges of uncertainty for the CHF for L40V05H3, L20V05H3, and L10V05H3 in microgravity are only 1.4, 1.9 and $1.8 \mathrm{~W} /$

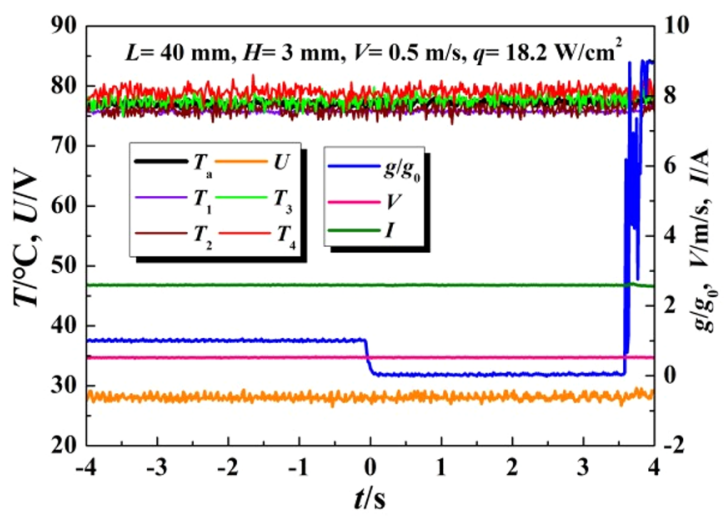

(a) $q=18.2 \mathrm{~W} / \mathrm{cm}^{2}[27,29]$ $\mathrm{cm}^{2}$, respectively, which are very close to each other. Bubbles are created on an artificial nucleation site between two-dimensional plates under terrestrial and microgravity conditions. It is well known that the bubbles tend to slide along the surface and coalesce to each other in microgravity compared to that in normal gravity due to the absence of gravity. Therefore, the bubble departure diameter is usually greater than that in normal gravity $[15,16,20,21,24-26]$. However, the influence of the gravity level on bubble behavior decreases with increasing flow velocity [15,16,20,21,24-26]. Ma and Chung [15] investigated the flow boiling heat transfer performance and boiling behavior of FC-72 with the subcooling of $26 \pm 2 \mathrm{~K}$ and a flow velocity of $0.078-0.3 \mathrm{~m} / \mathrm{s}$. Serret at al. [16] studied the bubble behavior of HFE-7100 confined vapor bubbles with the subcooling of approximately $5 \mathrm{~K}$ and a flow velocity of $2-6 \mathrm{~mm} / \mathrm{s}$. Celata et al. [20] and Baltis et al. [21] tested the flow boiling performance and flow pattern in FC-72 at the inlet subcooling of $9-30 \mathrm{~K}$ and flow velocity of $0.03-0.34 \mathrm{~m} / \mathrm{s}$. The flow velocity for $\mathrm{L} 40 \mathrm{~V} 05 \mathrm{H} 3, \mathrm{~L} 20 \mathrm{~V} 05 \mathrm{H} 3$, and $\mathrm{L} 10 \mathrm{~V} 05 \mathrm{H} 3$ is $0.5 \mathrm{~m} / \mathrm{s}$, which is much greater than that in Ref. $[15,16,20,21]$. Therefore, the bubble diameter in microgravity at $q=18.2 \mathrm{~W} / \mathrm{cm}^{2}, q=20.7 \mathrm{~W} / \mathrm{cm}^{2}$ in and $q=23.9 \mathrm{~W} / \mathrm{cm}^{2}$ is observed only slightly larger than those in normal gravity (See Fig. 4, Fig. A2 and Fig. A4). Although these three cases have the same flow velocity and channel height, there is still a little difference in bubble behavior between each other: the distinction of bubble behavior between normal gravity and microgravity becomes more significant with the increase of heater length. It was reported that the bubble coalescence becomes more distinct in microgravity at the downstream of the heating surface, and the flow boiling state is very sensitive to the bubble coalescence when the heat flux approaching the CHF [28]. Therefore, the flow boiling state for L40V05H3 (the longest heater) is most sensitive to the bubble coalescence among these three cases, and it is much easier to trigger the dramatical deterioration of the flow boiling heat transfer, resulting in the lowest CHF among these three cases.

According to the method mentioned above, the CHFs for L40V10H3 $(L=40 \mathrm{~mm}, V=1.0 \mathrm{~m} / \mathrm{s}$ and $H=3 \mathrm{~mm})$ and L40V05H5 $(L=40 \mathrm{~mm}$, $V=0.5 \mathrm{~m} / \mathrm{s}$ and $H=5 \mathrm{~mm}$ ) were measured in the ranges of 23.3-24.3 W/ $\mathrm{cm}^{2}$ and $19.8-21.2 \mathrm{~W} / \mathrm{cm}^{2}$, respectively (Figs. A5-A8). The CHF for L40V10H3 is much greater than that for L40V05H3. Therefore, the effects of the increased flow velocity on the flow boiling $\mathrm{CHF}$ and the bubble behavior is similar to the effects of decreased heater length. The origin is that the increased flow velocity reduces the bubble departure diameter, and then weakens the bubble coalescence and increases the CHF (as shown in Fig. A6). A similar phenomenon can also be found in Ref. [24-26,28,29]. On the one hand, it was found that

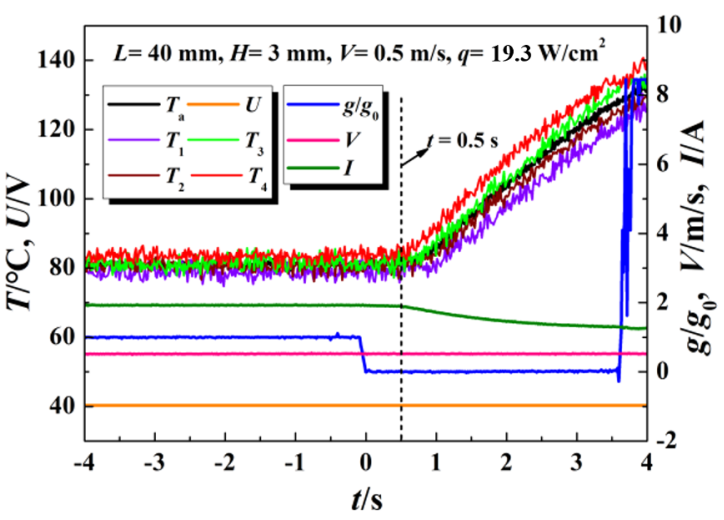

(b) $q=19.3 \mathrm{~W} / \mathrm{cm}^{2}$

Fig. 4. Comparison of the wall temperatures, heating voltage, heating current, and flow velocity in different gravity conditions for two levels of heat flux of L40V05H3. 


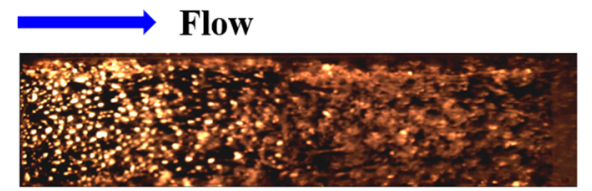

$t=\mathbf{- 0 . 1} \mathrm{s}$

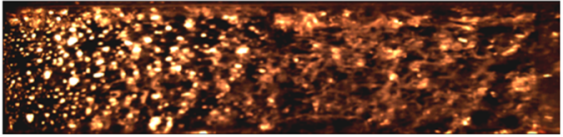

$t=0.3 \mathrm{~s}$

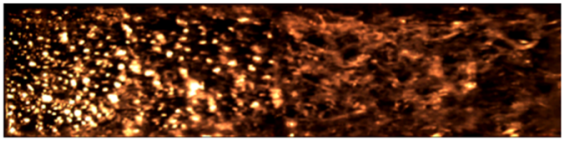

$t=1.0 \mathrm{~s}$

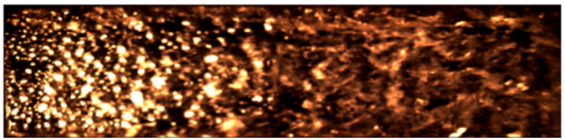

$t=2.0 \mathrm{~s}$

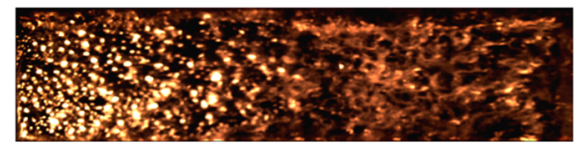

$t=3.6 \mathrm{~s}$

(a) $q=18.2 \mathrm{~W} / \mathrm{cm}^{2}[27,29]$

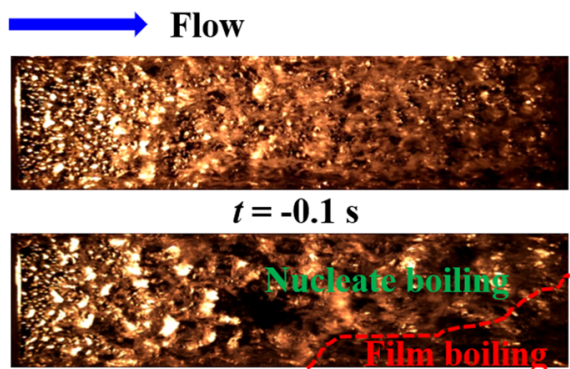

$t=0.3 \mathrm{~s}$

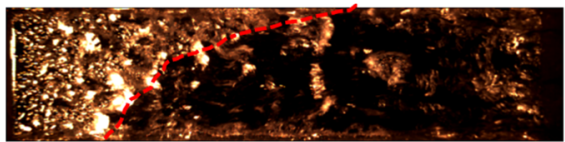

$t=1.0 \mathrm{~s}$

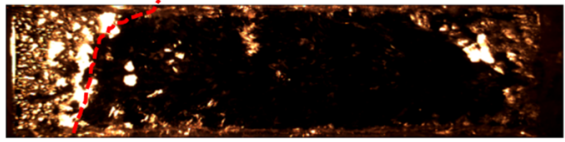

$t=2.0 \mathrm{~s}$

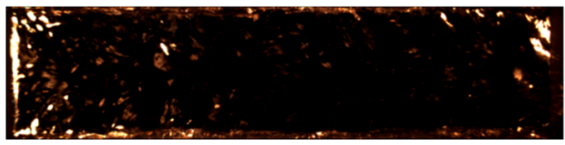

$t=3.6 \mathrm{~s}$

(b) $q=19.3 \mathrm{~W} / \mathrm{cm}^{2}$

Fig. 5. Comparison of bubble behavior in different gravity conditions for two levels of heat flux of L40V05H3. The gravity vector is into the page.

the accumulation of bubbles at the downstream of the heating surface is the main reason for heat transfer deterioration for the flow boiling with a small channel height and long heater [28,33,34]. Therefore, the higher channel is beneficial to achieve a higher CHF because it can reduce the accumulation of bubbles. On the other hand, the bubble tends to float up to the upper side of the channel in normal gravity, which causes the downstream of the heating surface to look blurry due to the overlap of the bubbles, as shown in Fig. A8. In addition, the downstream of the heating surface for L40V05H5 looks blurrier than that for L40V05H3, which means the increased of channel height is good for bubble lift-off and reduces the bubble coalescence on the heating surface. However, it is observed that the downstream of the heating surface looks clearer in microgravity compared to that in normal gravity, and the difference in bubble behavior between L40V05H5 and L40V05H3 is narrowed, as shown in Fig. 4 and Fig. A8. The reason is that the absence of gravity leads to the bubbles tending to slid on the surface instead of floating up to the upper side of the channel.

\subsection{The comparison of the CHF in microgravity}

The CHF for L40V05H3, L20V05H3, L10V05H3, L40V10H3, and L40V05H5 are in the ranges of $18.2-19.3 \mathrm{~W} / \mathrm{cm}^{2}, 20.7-22.5 \mathrm{~W} / \mathrm{cm}^{2}$, 23.9-25.6 W/ $\mathrm{cm}^{2}, 23.3-24.3 \mathrm{~W} / \mathrm{cm}^{2}$, and $19.8-21.2 \mathrm{~W} / \mathrm{cm}^{2}$, respectively. It was found that the CHF in microgravity increases with the increase of flow velocity and channel height, but decreases with the increase of heater length. A similar tendency in $q_{\text {CHF- } \mu \mathrm{g}} / q_{\text {CHF-1g }}$ was observed. The $q_{\mathrm{CHF}-\mathrm{\mu g}} / q_{\mathrm{CHF}-1 \mathrm{~g}}$ for L40V05H3, L20V05H3, L10V05H3, $\mathrm{L} 40 \mathrm{~V} 10 \mathrm{H} 3$, and L40V05H5 are in the ranges 77.8-83.8\%, 86.1-93.9\%, $88.3-95.0 \%, 88.1-92.2 \%$, and $81.0-87.1 \%$, respectively. Whereas, it is found that the increase of the $q_{\mathrm{CHF}-\mu \mathrm{g}} / q_{\mathrm{CHF}-\mathrm{gg}}$ for L40V05H5 is not as large as that of L40V10H3 compared to L40V05H3. As mentioned above, the bubble lift-off diameter in normal gravity is smaller than that in microgravity. In addition, the capillary length $\left(L_{C}=\left[\sigma / g\left(\rho_{1}-\rho_{g}\right)\right]^{0.5}\right)$ is approximately $0.76 \mathrm{~mm}$ in normal gravity, which is smaller than the height of the channel. Therefore, the higher channel is beneficial to ease the bubble accumulation at the downstream of the heating surface in normal gravity. However, the bubbles tend to slide on the surface, leading to more serious bubble coalescence on the heating surface [28], and the capillary length $(7.6 \mathrm{~mm})$ in microgravity gravity is larger than the channel height. Therefore, the effects of the channel height on the CHF in microgravity are not as large as that in normal gravity.

To find the critical velocity at which the effects of gravity can be negligible on the CHF of flow boiling ( $\left.q_{\mathrm{CHF}-\mu \mathrm{g}} / q_{\mathrm{CHF}-1 \mathrm{~g}} \geq 0.9\right)$, Zhang et al. proposed a set of criteria by the dimensionless analysis [34]. They found if the effects of gravity on the flow boiling CHF can be ignored, three conditions must be met:

$\frac{B o}{W e^{2}}=\frac{\left(\rho_{1}-\rho_{\mathrm{g}}\right)\left(\rho_{1}+\rho_{\mathrm{g}}\right)^{2} \sigma g}{\rho_{1}^{2} \rho_{\mathrm{g}}^{2} V^{4}} \leqslant 0.09$

$\frac{1}{F r}=\frac{\left(\rho_{1}-\rho_{\mathrm{g}}\right) g D_{h}}{\rho_{1} V^{2}} \leqslant 0.13$

$W e_{L}=\frac{\rho_{1} \rho_{\mathrm{g}} V^{2} L}{\left(\rho_{1}+\rho_{\mathrm{g}}\right) \sigma} \geqslant 2 \pi$

where $B o$ is the Bond numbers $\left(B o=g\left(\rho_{1}-\rho_{\mathrm{g}}\right) D_{\mathrm{h}}{ }^{2} / \sigma\right), W e_{L}$ is the Weber numbers based on heated length and $\mathrm{Fr}$ is the Froude number. According to the criteria, the relationship between the critical velocity and the heater length can be obtained, as shown in Fig. 6. It can be found from Fig. 6 that the critical velocity mainly depends on the 


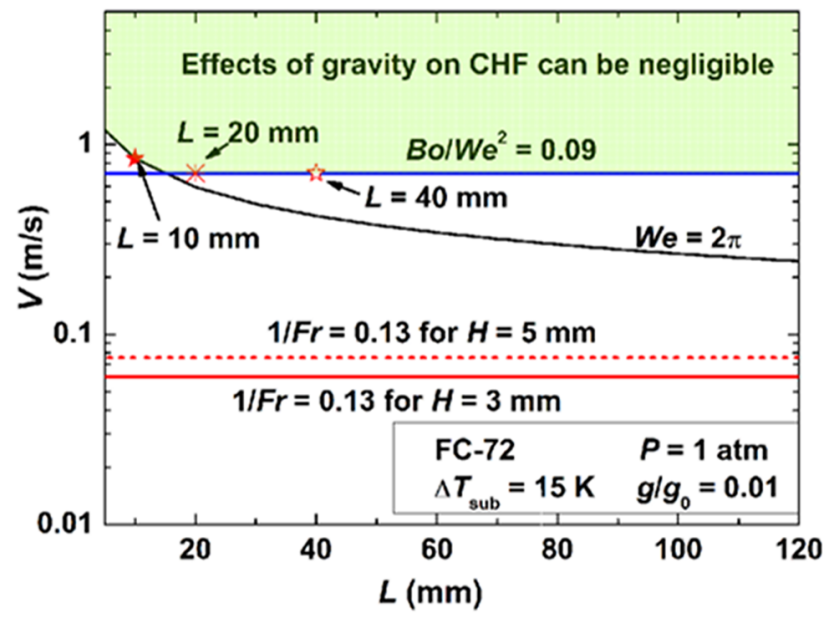

Fig. 6. The relationship of the critical flow velocity with the heater length.

criteria of $\mathrm{Bo} / \mathrm{We}^{2} \leq 0.09$ and $\mathrm{We} \geq 2 \pi$ in the present study, while the influence of the channel height can be negligible. In addition, the critical velocities for $L=10,20$ and $40 \mathrm{~mm}$ were calculated as $0.84,0.71$ and $0.71 \mathrm{~m} / \mathrm{s}$, respectively. However, the experimental results indicated that the $q_{\mathrm{CHF}-\mu \mathrm{g}} / q_{\mathrm{CHF}-1 \mathrm{~g}}$ for L20V05H03 and L10H05H03 are larger than 0.9 when $V=0.5 \mathrm{~m} / \mathrm{s}$. Therefore, except for the flow velocity, the effects of the heater length should be carefully considered when investigating the influences of gravity on the CHF of flow boiling.

\subsection{Dimensionless analysis of the $q_{C H F-\mu g} / q_{C H F-1 g}$}

Zhang et al. [28] analyzed effects of the heater length, channel geometrical parameter and surface modification on $q_{\mathrm{CHF}-\mu \mathrm{g}} / q_{\mathrm{CHF}-1 \mathrm{~g}}$, and developed an empirical correlation based on the dimensionless analysis, which can be expressed as

$q_{\mathrm{CHF}-\mu \mathrm{g}} / q_{\mathrm{CHF}-1 \mathrm{~g}}=0.179 \mathrm{We} e^{0.325} \mathrm{Ch}^{0.196} S f^{2.568}+\mathrm{K}$

where $C h$ is the dimensionless channel number and $S f$ is the dimensionless surface number $\left(S f=\mathrm{CHF}_{\mathrm{ss}, 1 \mathrm{~g}} / \mathrm{CHF}_{\mathrm{m}, 1 \mathrm{~g}}\right.$, represents the ratio of the CHF on smooth surface to the CHF on modified surface in normal gravity), respectively; $K$ is the $q_{\mathrm{CHF}-\mu \mathrm{g}} / q_{\mathrm{CHF}-1 \mathrm{~g}}$ in pool boiling $(V=0 \mathrm{~m} / \mathrm{s})$. $C h$ and $K$ are given by

$C h=\frac{p_{\mathrm{h}}}{p_{\mathrm{w}}} \frac{1}{E o} \frac{L}{L_{\mathrm{c}}}=\frac{p_{\mathrm{h}} L}{p_{\mathrm{w}} h^{2} \sqrt{g\left(\rho_{l}-\rho_{\mathrm{g}}\right) / \sigma}}$

$K=0.40 C h^{0.05} S f^{-0.64}$

where $p_{\mathrm{h}} / p_{\mathrm{w}}$ is the ratio of heated perimeter to the wetted perimeter, Eo is the Eötvös number $\left(E o=g\left(\rho_{1}-\rho_{g}\right) H^{2} / \sigma\right)$, represents the degree of confinement of the channel height [4].

The comparison of the experimental results and predicted data by Eq. (4) is shown in Fig. 7. Note that the deviation of heat flux for each case in the present study is only $1.9 \mathrm{~W} / \mathrm{cm}^{2}$. Therefore, the average value of $q_{\mathrm{CHF}-\mu \mathrm{g}} / q_{\mathrm{CHF}-1 \mathrm{~g}}$ for each case was used in Fig. 7 . It is found that remarkable deviations exist between the experimental results and predicted data for L40V05H3, L20V05H3, and L10V05H3. Although the development of Eq. (4) took the effects of the heater length, channel geometrical parameter and surface modification on $q_{\mathrm{CHF}-\mu \mathrm{g}} / q_{\mathrm{CHF}-1 \mathrm{~g}}$ into account, there are still some shortcomings for this correlation. Firstly, the development of Eq. (4) is based on the viewpoint of vapor accumulation in the channel. Therefore, the database in Ref. [28] is mainly

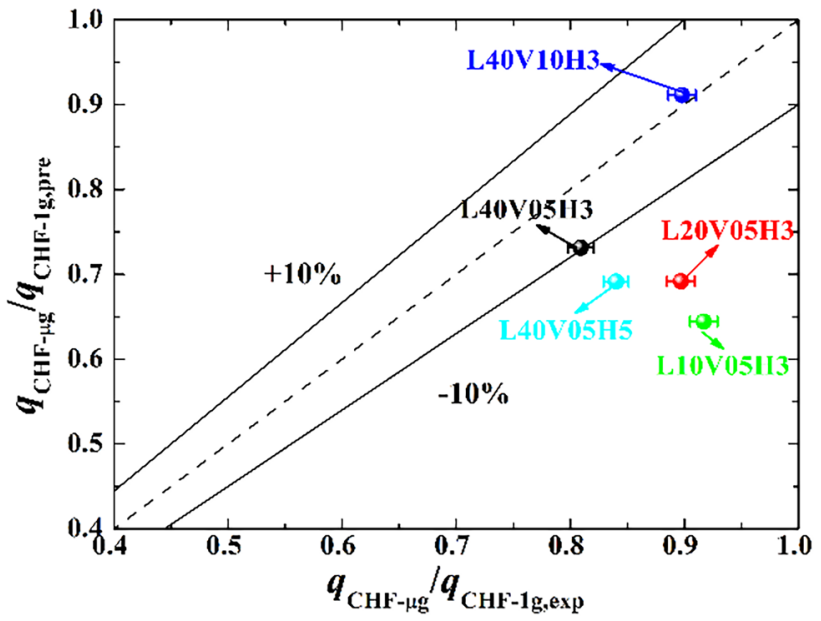

Fig. 7. Comparison of the experimental data and the predicted values of $q_{\mathrm{CHF}}$ $\mu \mathrm{g} / q_{\mathrm{CHF}-1 \mathrm{~g}}$ by the correlation in Ref. [28].

from the experimental results with the long heating surfaces of FC-72 (i.e. $L=101.6 \mathrm{~mm}$ in Ref. [24], $L=114.6 \mathrm{~mm}$ in Ref. [25]), and the threshold value for judging whether the vapor was accumulated or not in the channel was not given. For L20V05H3 and L10V05H3, the length of the heaters are only $10 \mathrm{~mm}$ and $20 \mathrm{~mm}$, respectively, and the vapor accumulation cannot be observed in these two cases, as shown in Fig. A2 and Fig. A4. Therefore, this correlation is not suitable to predict the $q_{\mathrm{CHF}-\mu \mathrm{g}} / q_{\mathrm{CHF}-1 \mathrm{~g}}$ for these two cases. For L40V05H3, the increased channel height eased the bubble accumulation to some extent. Therefore, this correlation may be not suitable to predict the $q_{\mathrm{CHF}-\mu \mathrm{g}} / q_{\mathrm{CHF}-1 \mathrm{~g}}$ for this case. Secondly, the same weight was assigned to the three factors $p_{\mathrm{h}} / p_{\mathrm{w}}, 1 /$ Eo and $L / L_{\mathrm{c}}$ in Eq. (4), but the sensitivity of $q_{\mathrm{CHF}-\mu \mathrm{g}} /$ $q_{\mathrm{CHF}-1 \mathrm{~g}}$ to these three factors are different. For instance, Kureta and Akimoto [35] found that the effects of the heated width on the CHF are small, but the CHF increases notably with the decrease of the heater length at the low inlet water temperature. Therefore, it is not accurate to assign the same weight to $p_{\mathrm{h}} / p_{\mathrm{w}}, 1 / E o$, and $L / L_{\mathrm{c}}$ when developing the correlation for the $q_{\mathrm{CHF}-\mu \mathrm{g}} / q_{\mathrm{CHF}-1 \mathrm{~g}}$ prediction. Thirdly, the points of the database for the flow boiling CHF in microgravity are very limited, therefore, the scope of application is narrow, and the modification and improvement of the correlation are inevitable as the experimental data increase.

To improve the correlation, the factors that affect the $q_{\mathrm{CHF}-\mu \mathrm{g}} / q_{\mathrm{CHF}-1 \mathrm{~g}}$ should be considered carefully. In the present study, the effects of $p_{\mathrm{h}} /$ $p_{\mathrm{w}}, E o$, and $L / L_{\mathrm{c}}$ on $q_{\mathrm{CHF}-\mu \mathrm{g}} / q_{\mathrm{CHF}-1 \mathrm{~g}}$ were analyzed respectively instead of assigning the same weight to the three factors. Then, Eq. (4) can be rewritten as

$$
\begin{gathered}
q_{\mathrm{CHF}-\mu \mathrm{g}} / q_{\mathrm{CHF}-1 \mathrm{~g}}=a W e^{b}\left(\frac{p_{\mathrm{h}}}{p_{\mathrm{w}}}\right)^{c} E o^{d}\left(\frac{L}{L_{\mathrm{c}}}\right)^{e} S f^{f}+K \\
K=0.40 C h^{0.05} S f^{-0.64}
\end{gathered}
$$

where $S f=1$ in the present study because only the CHF results on the smooth surface were measured in the present study and most of the data from literature are based on the smooth surface. Note that $K$ is based on the data of pool boiling. Therefore, it is not necessary to revise the expression of $K$. Then, the correlation for the prediction of the flow boiling $q_{\mathrm{CHF}-\mu \mathrm{g}} / q_{\mathrm{CHF}-1 \mathrm{~g}}$ on the smooth surface can be expressed as

$q_{\mathrm{CHF}-\mu \mathrm{g}} / q_{\mathrm{CHF}-1 \mathrm{~g}}=a W e^{b}\left(\frac{p_{\mathrm{h}}}{p_{\mathrm{w}}}\right)^{c} E o^{d}\left(\frac{L}{L_{\mathrm{c}}}\right)^{e}+0.40 C h^{0.05}$ 
Table 2

The $q_{\text {CHF- } \mu \mathrm{g}} / q_{\text {CHF-1g }}$ results based on the ground tests using FC-72 as the working fluid.

\begin{tabular}{|c|c|c|c|c|c|c|c|}
\hline$L(\mathrm{~mm})$ & $V(\mathrm{~m} / \mathrm{s})$ & $H(\mathrm{~mm})$ & $\begin{array}{l}q_{\mathrm{CHF}-} \\
\mathrm{o}^{\circ} \\
(\mathrm{W} / \\
\left.\mathrm{cm}^{2}\right)\end{array}$ & $\begin{array}{l}q_{\mathrm{CHF}-} \\
315^{\circ} \\
(\mathrm{W} / \\
\left.\mathrm{cm}^{2}\right)\end{array}$ & $\begin{array}{l}q_{\mathrm{CHF}-} \\
135^{\circ} \\
(\mathrm{W} / \\
\left.\mathrm{cm}^{2}\right)\end{array}$ & $\begin{array}{l}\text { range of } \\
q_{C H F-\mu g} / q_{C H F-} \\
1 g\end{array}$ & $\begin{array}{l}\text { average } \\
\text { value of } \\
q_{C H F-\mu g} / \\
q_{C H F-1 g}\end{array}$ \\
\hline 40 & 0.75 & 3 & 25.3 & 20.3 & 22.8 & $80.0-89.8 \%$ & 0.849 \\
\hline 20 & 0.75 & 3 & 28.6 & 25.9 & 27.6 & $89.1-96.6 \%$ & 0.937 \\
\hline 10 & 0.75 & 3 & 31.0 & 28.8 & 30.4 & $92.9-97.8 \%$ & 0.954 \\
\hline 20 & 1.0 & 3 & 30.9 & 28.7 & 29.8 & $92.9-96.7 \%$ & 0.948 \\
\hline 10 & 1.0 & 3 & 35.8 & 34.3 & 35.3 & $95.8-98.6 \%$ & 0.972 \\
\hline 20 & 0.5 & 5 & 24.8 & 20.7 & 22.5 & $83.5-90.8 \%$ & 0.871 \\
\hline 10 & 0.5 & 5 & 28.8 & 24.9 & 26.8 & $86.5-93.1 \%$ & 0.898 \\
\hline 40 & 0.75 & 5 & 25.5 & 20.8 & 23.8 & $81.3-93.3 \%$ & 0.873 \\
\hline 20 & 0.75 & 5 & 26.0 & 22.4 & 25.2 & $86.2-96.9 \%$ & 0.916 \\
\hline 10 & 0.75 & 5 & 33.5 & 30.8 & 31.8 & $92.0-94.9 \%$ & 0.934 \\
\hline 40 & 1.0 & 5 & 26.4 & 23.7 & 25.5 & $89.5-96.7 \%$ & 0.930 \\
\hline 20 & 1.0 & 5 & 29.0 & 26.3 & 28.3 & $90.7-97.7 \%$ & 0.942 \\
\hline 10 & 1.0 & 5 & 36.9 & 35.3 & 35.8 & $95.7-97.0 \%$ & 0.963 \\
\hline
\end{tabular}

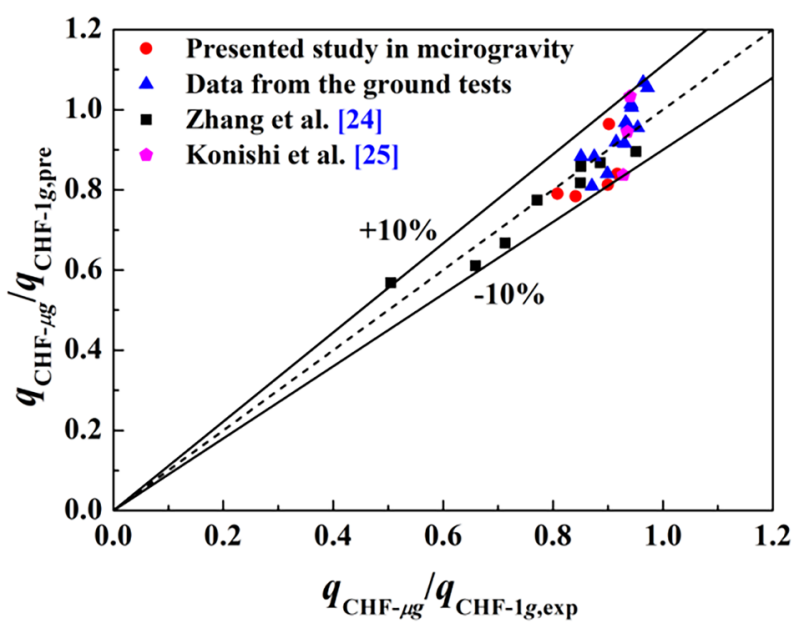

Fig. 8. Comparison of the experimental data and the predicted values of $q_{\mathrm{CHF}-}$ ${ }_{\mu \mathrm{g}} / q_{\mathrm{CHF}-1 \mathrm{~g}}$ by the improved correlation.

As mentioned above, the points of the database used to fit Eq. (4) are too limited to ensure the high precision and large scope of application of the correlation. Therefore, the number of points in the database was increased in the present study. Firstly, the five points from drop tower experiments are used in the present study. Secondly, Ref. [29] has provided a criterion for approximating the flow boiling CHF in microgravity by ground tests, in which the CHF in microgravity can be approximated by the range of CHF under the inclinations of $315^{\circ}$ and $135^{\circ}$ in normal gravity. The scope of application for this criterion is $V=0.5-1.0 \mathrm{~m} / \mathrm{s}, L=10-40 \mathrm{~mm}, H=3-5 \mathrm{~mm}$ with the subcooling of $15 \mathrm{~K}$ at $1 \mathrm{~atm}$. Therefore, the CHF data based on the ground tests are also measured and carefully used in the present study according to the scope of application of the criterion. The results based on the ground tests are listed in Table 2. Then, the constants $a, b, c, d$, and $e$ can be obtained by fitting the data in Ref. $[24,25]$ and that in the present study, and the correlation can be expressed as follows:

$q_{\mathrm{CHF}-\mu \mathrm{g}} / q_{\mathrm{CHF}-1 \mathrm{~g}}=0.473 W e^{0.299}\left(\frac{p_{\mathrm{h}}}{p_{\mathrm{w}}}\right)^{0.155} E o^{-0.04}\left(\frac{L}{L_{\mathrm{c}}}\right)^{-0.153}+0.40 C h^{0.05}$
The experimental data covered for fitting the correlation in the present study are for subcooled flow boiling with the following range of parameters: inlet velocity $V=0.2-1.9 \mathrm{~m} / \mathrm{s}$; length of heater $L=10-114.6 \mathrm{~mm}$; subcooling $\Delta T_{\text {sub }}=3-15 \mathrm{~K}$; and channel of height $H=3-5 \mathrm{~mm}$.

The experimental results and predicted data by improved correlation are compared in Fig. 8. It can be found that the calculated results are in good agreement with the experimental data with a deviation of $\pm 10 \%$. Therefore, when predicting the $q_{\mathrm{CHF}-\mu \mathrm{g}} / q_{\mathrm{CHF}-1 \mathrm{~g}}$, it is more reasonable to consider the effects of $p_{\mathrm{h}} / p_{\mathrm{w}}, E o$ and $L / L_{\mathrm{c}}$ separately.

It is found from Eq. (9) We has the maximum exponent in Eq. (9), indicating that flow velocity shows the strongest effect on $q_{\mathrm{CHF}-\mu \mathrm{g}} / q_{\mathrm{CHF}}$ ${ }_{1 \mathrm{~g}}$ and $q_{\mathrm{CHF}-\mu \mathrm{g}} / q_{\mathrm{CHF}-1 \mathrm{~g}}$ can be increased significantly by increasing flow velocity. In addition, $p_{\mathrm{h}} / p_{\mathrm{w}}$ and $L / L_{\mathrm{c}}$ also play important roles in $q_{\mathrm{CHF}}$ ${ }_{\mu \mathrm{g}} / q_{\mathrm{CHF}-1 \mathrm{~g}}$. A notable increase of $q_{\mathrm{CHF}-\mu \mathrm{g}} / q_{\mathrm{CHF}-1 \mathrm{~g}}$ can also be obtained by increasing $p_{\mathrm{h}} / p_{\mathrm{w}}$ or/and decrease the heater length. While the exponent of $E o=-0.04$, is much smaller than those of $p_{\mathrm{h}} / p_{\mathrm{w}}, E o$ and $L / L_{\mathrm{c}}$. Therefore, $q_{\mathrm{CHF}-\mu \mathrm{g}} / q_{\mathrm{CHF}-1 \mathrm{~g}}$ is not sensitive to the channel height when the channel height is in the range of 3-5 mm. Baldassari and Marengo [4] pointed out that the Eötvös number plays an important role in flow boiling heat transfer when the gravity tends to zero or when the tube diameter tends to zero. However, the range of the channel height in the present study is very narrow $(H=3-5 \mathrm{~mm}$, and the corresponding range of $E o$ is 0.157-0.437). Therefore, the effects of the channel height (or $E$ o) on $q_{\text {CHF- } \mu \mathrm{g}} / q_{\text {CHF-1g }}$ should be investigated further in future studies.

\section{Conclusions}

In the present study, the CHF of subcooled flow boiling in a singleside heated rectangular channel at different gravity levels on smooth silicon surfaces was investigated by drop tower experiments. The heat transfer performance, including the CHF, wall temperatures and bubble behavior were measured. The main findings from the study are concluded as follows:

(1) The CHF increases with the increase of the channel height and flow velocity, but decreases with the increase of the heater length. A similar tendency was found for $q_{\mathrm{CHF}-\mu \mathrm{g}} / q_{\mathrm{CHF}-1 \mathrm{~g}}$.

(2) The distinction of bubble behavior between normal gravity and microgravity becomes more sensitive to the increase of the heater length.

(3) With the increase of the heater length or the decrease of the flow velocity and channel height, the flow boiling state is more sensitive to the bubble coalescence, which makes it easier to transit from the nucleate boiling to film boiling.

(4) The dimensionless analysis for the influences of $W e, p_{\mathrm{h}} / p_{\mathrm{w}}$, Eo and $L / L_{\mathrm{c}}$ was conducted based on the data of this study and the literature. $W e, p_{\mathrm{h}} / p_{\mathrm{w}}$ and $L / L_{\mathrm{c}}$ show the notable effects on $q_{\mathrm{CHF}-\mu \mathrm{g}} / q_{\mathrm{CHF}-}$ 1g, while $q_{\mathrm{CHF}-\mu \mathrm{g}} / q_{\mathrm{CHF}-1 \mathrm{~g}}$ is not sensitive to Eo. $q_{\mathrm{CHF}-\mu \mathrm{g}} / q_{\mathrm{CHF}-1 \mathrm{~g}}$ can be increased significantly by increasing $W e, p_{\mathrm{h}} / p_{\mathrm{w}}$ or/and decrease the heater length. An improved correlation for the prediction of $q_{\mathrm{CHF}}$ ${ }_{\mu \mathrm{g}} / q_{\mathrm{CHF}-1 \mathrm{~g}}$ was developed based on the dimensionless analysis and it shows good agreements with the experimental data.

\section{Declaration of Competing Interest}

The authors declare that they have no known competing financial interests or personal relationships that could have appeared to influence the work reported in this paper. 


\section{Acknowledgements}

This work is supported by the project of Young Elite Scientists Sponsorship Program by CAST (2018QNRC001), Joint ESA-CMSA Project (TGMTYY00-RW-05-1.00), National Natural Science Foundation of China (No. 51976163, No.51636006), Funds of
International Cooperation and Exchange of the National Natural Science Foundation of China (Research collaboration NSFC-VR) (No. 51961135102), and Shaanxi Creative Talents Promotion PlanTechnological Innovation Team (2019TD-039). China Scholarship Council (CSC) is kindly acknowledged. Mr. Bin Liu is a visiting PhD student at University of Pisa.

\section{Appendix A. . The flow boiling performance and bubble behavior of L20V05H3, L10V05H3, L40V10H3 and L40V05H5}

The comparison of the wall temperatures, heating voltage, heating current, and flow velocity in different gravity conditions for L20V05H3 is shown in Fig. A1Fig. A3 and the comparison of bubble behavior at different gravity levels for this case are shown in Fig. A2. As shown in Fig. A1, the wall temperatures increase slightly in microgravity conditions at $q=20.7 \mathrm{~W} / \mathrm{cm}^{2}$. However, the stable nucleate flow boiling is still maintained at this heat flux, and almost no difference in bubble behavior can be observed, as shown in Fig. A2. When the heat flux is increased to $22.5 \mathrm{~W} / \mathrm{cm}^{2}$, the wall temperatures increase dramatically at $t=0.8 \mathrm{~s}$, and the nucleate flow boiling transit to the film boiling within $2 \mathrm{~s}$. Therefore, the CHF in microgravity can be inferred in the range of $20.7-22.5 \mathrm{~W} / \mathrm{cm}^{2}$ for this case.

The comparison of the wall temperatures, heating voltage, heating current, and flow velocity in different gravity conditions for L10V05H3 is shown in . The wall temperature remains stable at $q=23.9 \mathrm{~W} / \mathrm{cm}^{2}$, while it increases dramatically at $0.4 \mathrm{~s}$ at $q=25.6 \mathrm{~W} / \mathrm{cm}^{2}$. Similar to the L40V05H3 and L20V05H3, the CHF in microgravity for L10V05H3 can be inferred in the range of $23.9-25.6 \mathrm{~W} / \mathrm{cm}^{2}$. The bubble behavior at $q=23.9 \mathrm{~W} / \mathrm{cm}^{2}$ is similar to that for L40V05H3 and L20V05H3, As shown in Fig. A4. However, it transits to film boiling within $1 \mathrm{~s}$, which is much faster than that of L40V05H3 and L20V05H3. The CHF in microgravity increases with the decrease of the heater length, while the time from nucleate boiling to film boiling decreases as the length of the heater decreases.

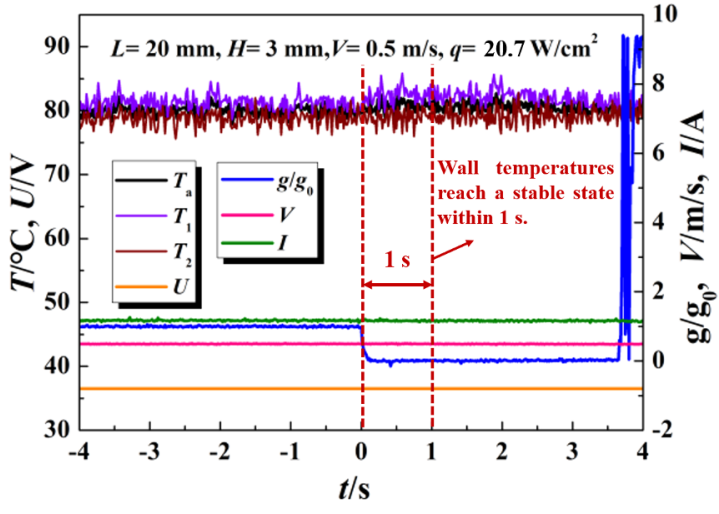

(a) $q=20.7 \mathrm{~W} / \mathrm{cm}^{2}$

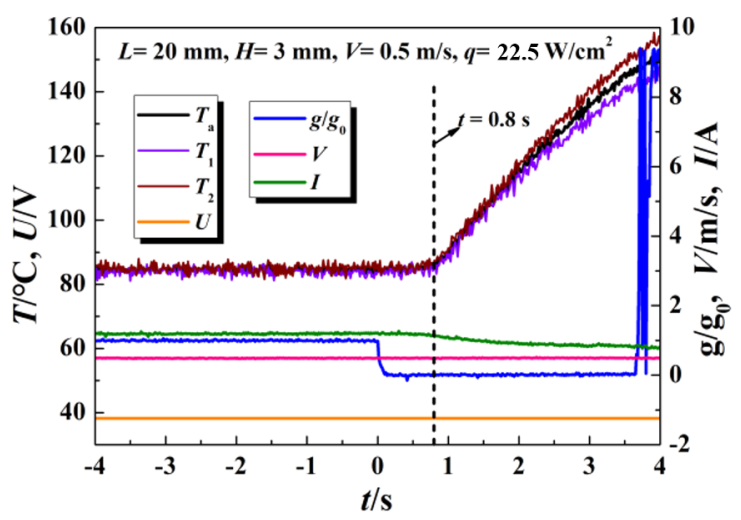

(b) $q=22.5 \mathrm{~W} / \mathrm{cm}^{2}$

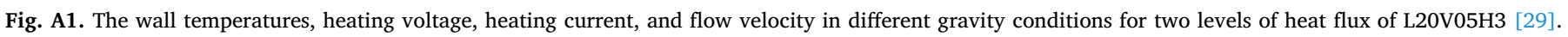

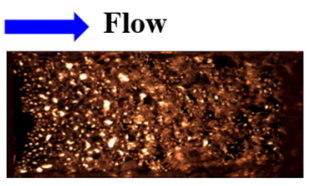

$t=-\mathbf{0 . 1} \mathrm{s}$

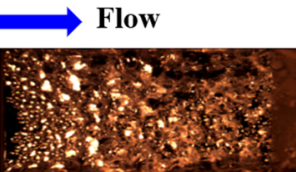

$t=-0.1 \mathrm{~s}$

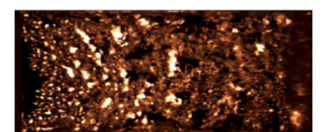

$t=0.7 \mathrm{~s}$

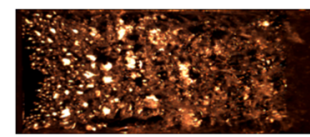

$t=2.0 \mathrm{~s}$

(a) $q=20.7 \mathrm{~W} / \mathrm{cm}^{2}$

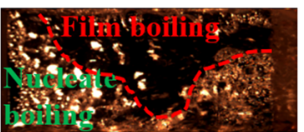

$t=0.7 \mathrm{~s}$

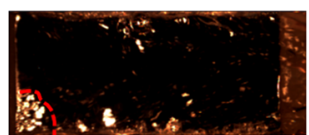

$t=1.0 \mathrm{~s}$

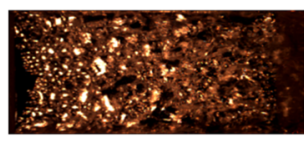

$t=3.6 \mathrm{~s}$

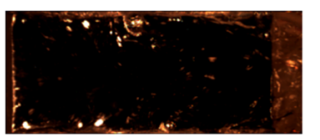

$t=2.0 \mathrm{~s}$

(b) $q=22.5 \mathrm{~W} / \mathrm{cm}^{2}$

Fig. A2. Comparison of bubble behavior in different gravity conditions for two levels of heat flux of L20V05H3 [29]. The gravity vector is into the page. 


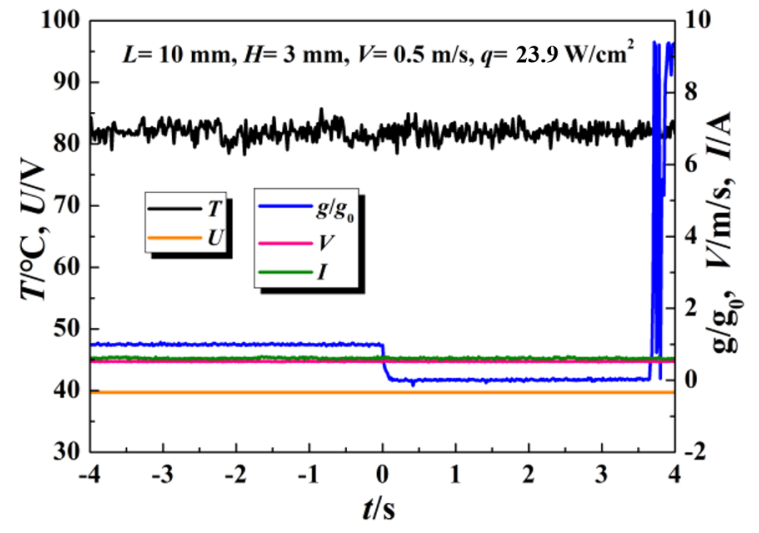

(a) $q=23.9 \mathrm{~W} / \mathrm{cm}^{2}$

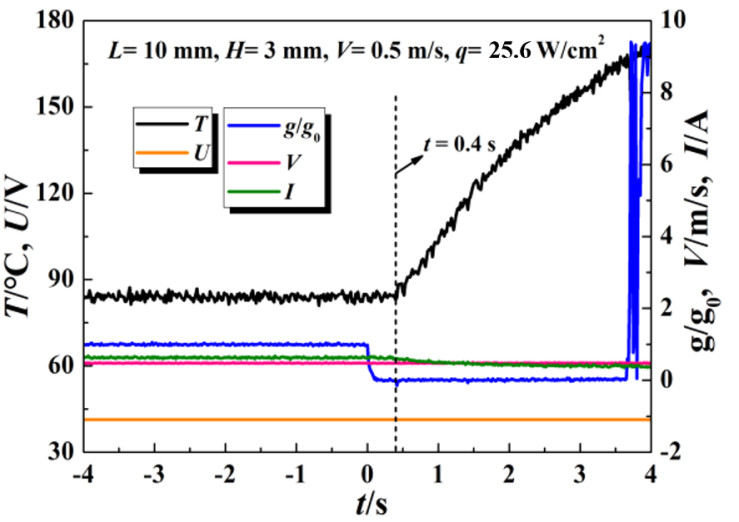

(b) $q=25.6 \mathrm{~W} / \mathrm{cm}^{2}$

Fig. A3. The wall temperatures, heating voltage, heating current, and flow velocity in different gravity conditions for two levels of heat flux of L10V05H3.

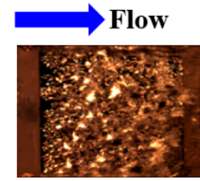

$t=-0.1 \mathrm{~s}$

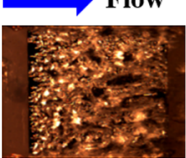

$t=-0.1 \mathrm{~s}$

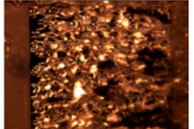

$t=0.3 \mathrm{~s}$

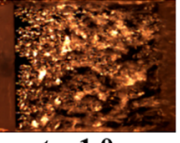

$t=1.0 \mathrm{~s}$

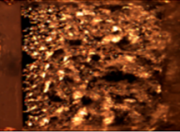

$t=3.6 \mathrm{~s}$

(a) $q=23.9 \mathrm{~W} / \mathrm{cm}^{2}$

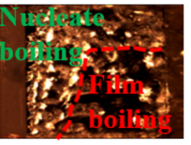

$t=0.3 \mathrm{~s}$

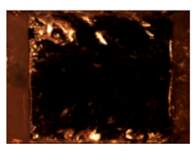

$t=0.5 \mathrm{~s}$

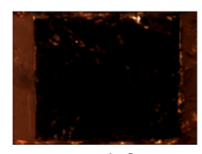

$t=1.0 \mathrm{~s}$

(b) $q=25.6 \mathrm{~W} / \mathrm{cm}^{2}$

Fig. A4. Comparison of bubble behavior in different gravity conditions for two levels of heat flux of L10V05H3. The gravity vector is into the page.

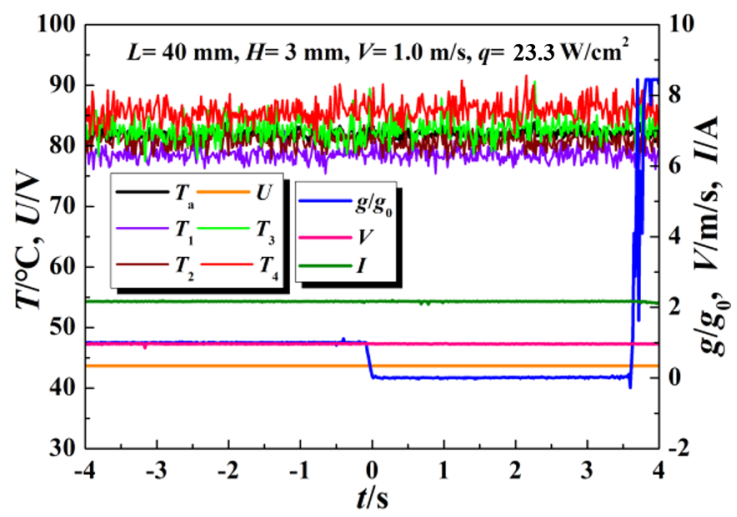

(a) $q=23.3 \mathrm{~W} / \mathrm{cm}^{2}$

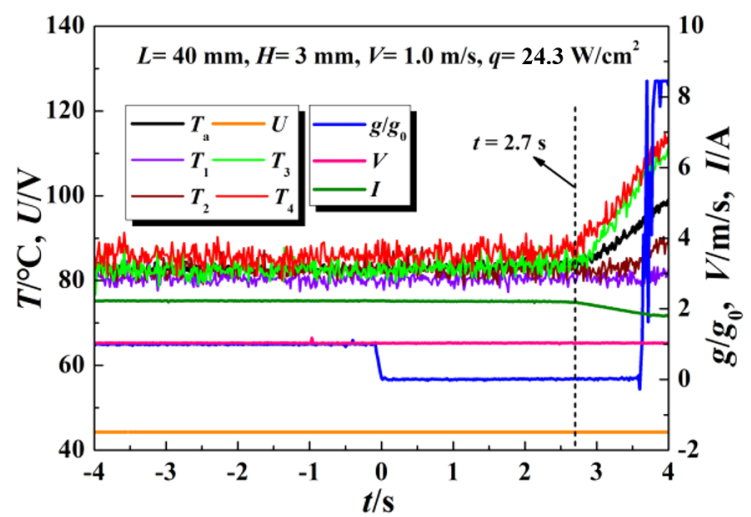

(b) $q=24.3 \mathrm{~W} / \mathrm{cm}^{2}$

Fig. A5. The wall temperatures, heating voltage, heating current, and flow velocity in different gravity conditions for two levels of heat flux of L40V10H3. 


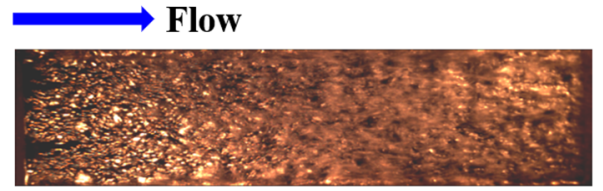

$t=\mathbf{- 0 . 1} \mathrm{s}$

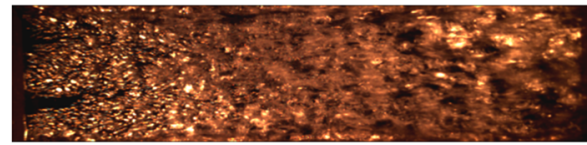

$$
t=1.0 \mathrm{~s}
$$

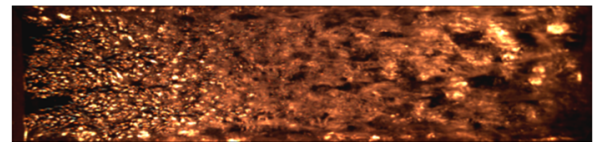

$t=2.4 \mathrm{~s}$

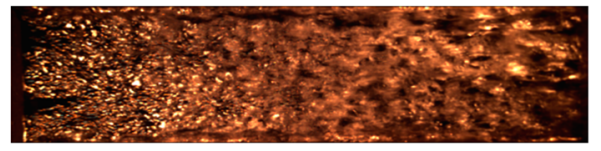

$t=2.8 \mathrm{~s}$

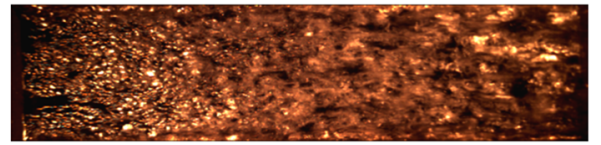

$t=3.6 \mathrm{~s}$

(a) $q=23.3 \mathrm{~W} / \mathrm{cm}^{2}$

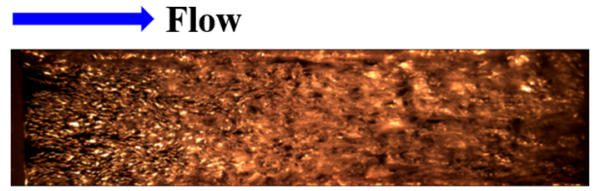

$t=\mathbf{- 0 . 1} \mathrm{s}$

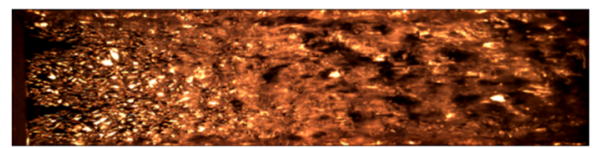

$t=1.0 \mathrm{~s}$

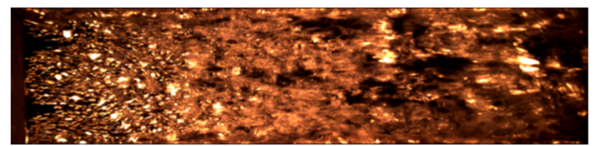

$t=2.4 \mathrm{~s}$

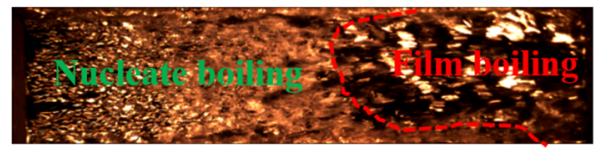

$t=2.8 \mathrm{~s}$

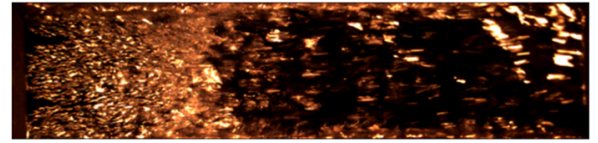

$t=3.6 \mathrm{~s}$

(b) $q=24.3 \mathrm{~W} / \mathrm{cm}^{2}$

Fig. A6. Comparison of bubble behavior in different gravity conditions for two levels of heat flux of L40V10H3. The gravity vector is into the page.

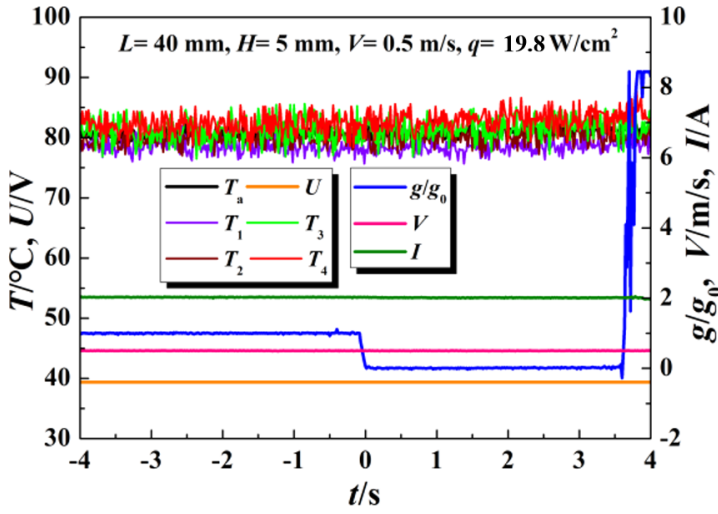

(a) $q=19.8 \mathrm{~W} / \mathrm{cm}^{2}$

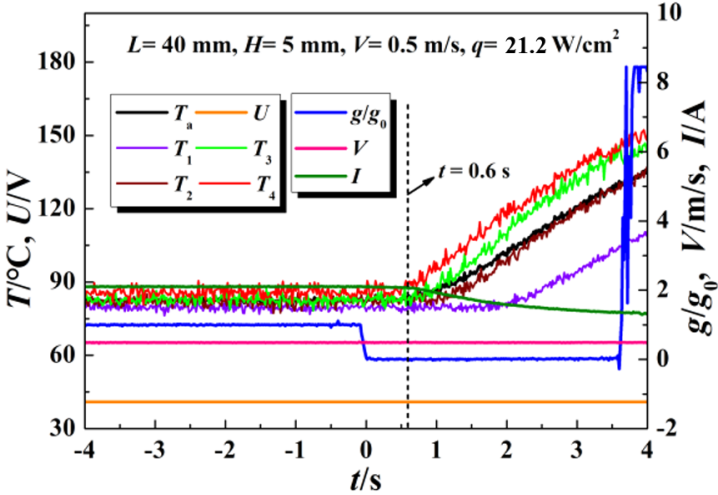

(b) $q=21.2 \mathrm{~W} / \mathrm{cm}^{2}$

Fig. A7. The wall temperatures, heating voltage, heating current, and flow velocity in different gravity conditions for two levels of heat flux of L40V05H5.

Using the same method shown above, the CHF for L40V10H3 and L40V05H5 can be obtained in the ranges of $23.3-24.3 \mathrm{~W} / \mathrm{cm}^{2}$ and 19.8-21.2 W/ $\mathrm{cm}^{2}$, respectively (as shown in Fig. A5 and Fig. A7). It can be observed that the flow boiling maintained stable from $0 \mathrm{~s}$ to $2.7 \mathrm{~s}$, as shown in Fig. A6, and the transition of the flow boiling is much slower than that for L40V10H3, suggesting that the increasing flow velocity slows down the transition process of flow boiling. As for L40V05H5, the bubble coalescence becomes much seriously in microgravity although the wall temperatures remain steady at $19.8 \mathrm{~W} / \mathrm{cm}^{2}$ (see Fig. A8). The flow boiling completely converts to film boiling within $3 \mathrm{~s}$, which is similar to that for L40V05H3. In addition, the CHF for L40V05H5 is only slightly increased compared to that for L40V05H5, which indicates the effects of the increased channel height on the CHF is not as large as that of the increased flow velocity. 


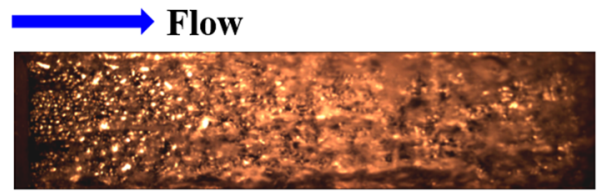

$t=\mathbf{- 0 . 1} \mathrm{s}$

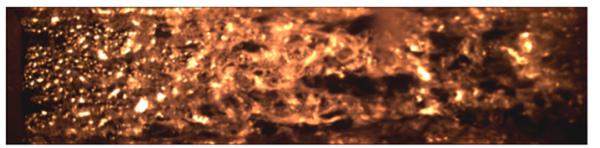

$t=0.5 \mathrm{~s}$

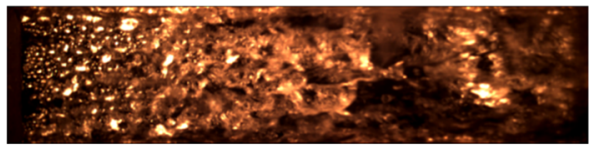

$t=0.7 \mathrm{~s}$

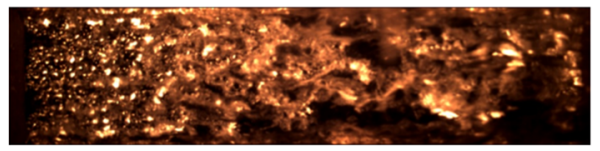

$t=2.0 \mathrm{~s}$

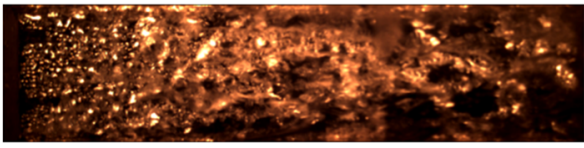

$t=3.6 \mathrm{~s}$

(a) $q=19.8 \mathrm{~W} / \mathrm{cm}^{2}$

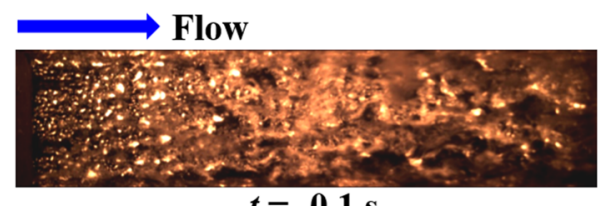

$t=-0.1 \mathrm{~s}$

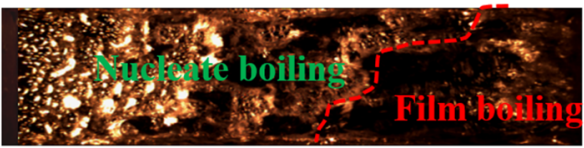

$t=0.5 \mathrm{~s}$

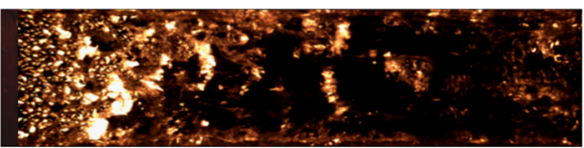

$t=0.7 \mathrm{~s}$

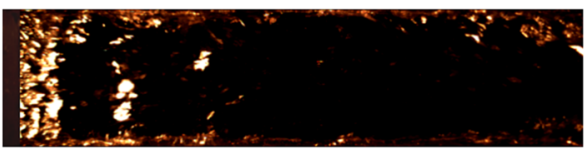

$t=2.0 \mathrm{~s}$

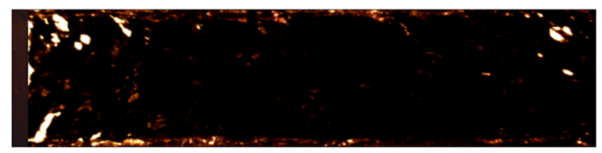

$t=3.0 \mathrm{~s}$

(b) $q=21.2 \mathrm{~W} / \mathrm{cm}^{2}$

Fig. A8. Comparison of bubble behavior in different gravity conditions for two levels of heat flux of L40V05H5. The gravity vector is into the page.

Appendix B. . Wall temperature evolution during the drop tower experiments.

To ensure that the duration of the drop tower experiment ( $3.5 \mathrm{~s}$ ) is sufficient for the present study, it is very important to verify the evolution of wall temperature during the drop tower experiment. Before entering the microgravity environment, the stable boiling heat transfer state has been reached. After entering the microgravity, there is a certain increase in the wall temperature, which causes a decrease in the heat transfer coefficient. To verify the wall temperature during the drop tower experiments, A simple transient thermal conductivity simulation was carried out by commercial software (Comsol 5.5). In the present study, the maximum temperature increase (approximate $1.5{ }^{\circ} \mathrm{C}$ ) after entering microgravity can be observed from L20V05H3 at $q=20.7 \mathrm{~W} / \mathrm{cm}^{2}$, which means that the change of gravity level under this condition will cause the most obvious disturbance to heat transfer. Therefore, this case was used for simulation. It should be noted that all the cases which have reached the CHF are not taken into consideration because they have reached CHF and are still in an unstable state at $t=3.5 \mathrm{~s}$. To approximate the boiling heat transfer, the boiling heat transfer coefficient was applied onto the silicon surface. The silicon surface was treated as a body heat source with a heat flux of $4.2 \times 10^{8} \mathrm{~W} / \mathrm{m}^{3}$. The model and boundary conditions are shown in Fig. B1.

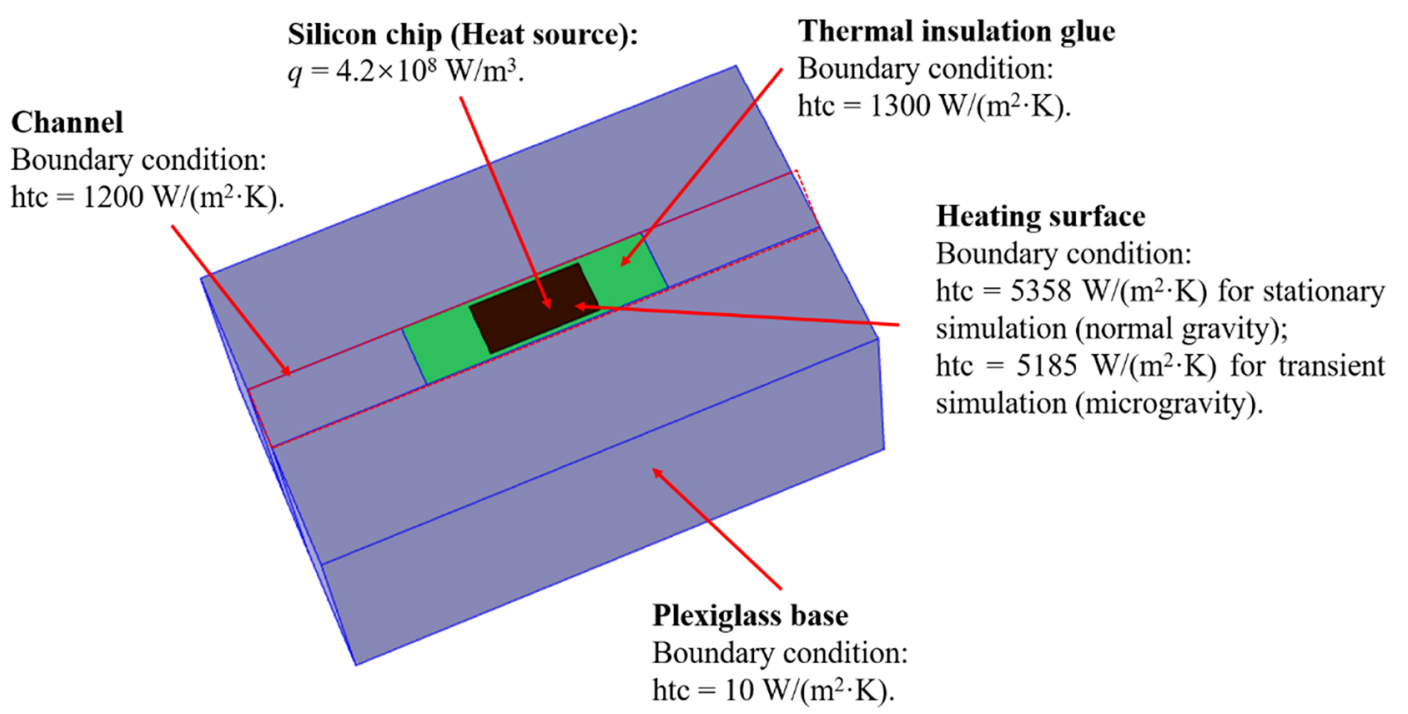

Fig. B1. The 3-D model and boundary conditions for the transient thermal conductivity simulation of $\mathrm{L} 20 \mathrm{~V} 05 \mathrm{H} 3$ at $q=20.7 \mathrm{~W} / \mathrm{cm}^{2}$. 


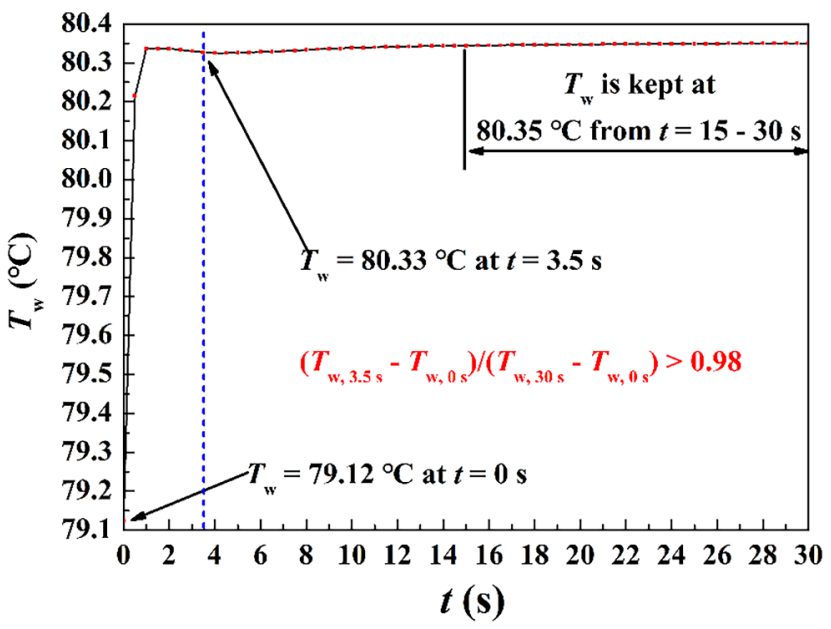

Fig. B2. The evolution of the wall temperature during the transient simulation.

Before the transient thermal conductivity simulation, a stationary thermal conductivity simulation based on the normal gravity conditions was carried out by applying the heat transfer coefficient of $5385 \mathrm{~W} /\left(\mathrm{m}^{2} \cdot \mathrm{K}\right)$. Then, the transient simulation was carried out based on the results of the stationary thermal conductivity simulation. A heat transfer coefficient of $5185 \mathrm{~W} /\left(\mathrm{m}^{2} \cdot \mathrm{K}\right)$ was applied on the heating surface. The transient time was set as $30 \mathrm{~s}$ with a step of $0.5 \mathrm{~s}$.

The evolution of wall average temperature is shown in Fig. B2. It can be seen from the figure below that the wall temperature increases very significantly after entering microgravity. With the increase of time, the rate of wall temperature increase decreases rapidly. The average wall temperatures are increased to $80.33^{\circ} \mathrm{C}$ at $t=3.5 \mathrm{~s}$, which are very close to the wall temperature at $t=30 \mathrm{~s}\left(80.35{ }^{\circ} \mathrm{C}\right)$. Therefore, it can be considered that the boiling states for the lower heat flux of all the 5 cases have reached the steady-state during the drop tower experiments.

\section{References}

[1] I. Mudawar, Assessment of high-heat-flux thermal management schemes, IEEE Trans. Compon. Packag. Technol. 24 (2) (2001) 122-141.

[2] J.C. Chen, Correlation for boiling heat transfer to saturated fluids in convective flow, Ind. Eng. Chem. Proc. Des. Dev. 5 (3) (1966) 322-329.

[3] M. Yuan, J. Wei, Y. Xue, J. Fang, Subcooled flow boiling heat transfer of FC-72 from silicon chips fabricated with micro-pin-fins, Int. J. Therm. Sci. 48 (7) (2009) 1416-1422.

[4] C. Baldassari, M. Marengo, Flow boiling in microchannels and microgravity, Prog. Energy Combust. Sci. 39 (1) (2013) 1-36.

[5] P. Di Marco, Review of reduced gravity boiling heat transfer: European research, Therm. Eng. Microgravity 20 (4) (2003) 252-263.

[6] H. Ohta, Review of reduced gravity boiling heat transfer: Japanese research, J. Jpn. Soc. Microgravity Appl. 20 (4) (2003) 272-285.

[7] J. Kim, Review of reduced gravity boiling heat transfer: US research, Therm. Eng. Microgr. 20 (4) (2003) 264-271.

[8] J.F. Zhao, Two-phase flow and pool boiling heat transfer in microgravity, Int. J. Multiphase Flow 36 (2) (2010) 135-143.

[9] C. Konishi, I. Mudawar, Review of flow boiling and critical heat flux in microgravity, Int. J. Heat Mass Transf. 80 (2015) 469-493.

[10] Y. Ma, J.N. Chung, An experimental study of forced convection boiling in microgravity, Int. J. Heat Mass Transf. 41 (1998) 2371-2382.

[11] M. Saito, N. Yamaoka, K. Miyazaki, M. Kinoshita, Y. Abe, Boiling two-phase flow under microgravity, Nucl. Eng. Des. 146 (1994) 451-461.

[12] S. Luciani, D. Brutin, C. Le Niliot, O. Rahli, L. Tadrist, Flow Boiling in minichannels under mormal, hyper and microgravity: local heat transfer analysis using inverse methods, J. Heat Transfer 130 (10) (2008) 101502.

[13] D. Brutin, V.S. Ajaev, L. Tadrist, Pressure drop and void fraction during flow boiling in rectangular minichannels in weightlessness, Appl. Therm. Eng. 51 (1-2) (2013) $1317-1327$.

[14] T.H. Cochran, Forced-convection boiling near inception in zero-gravity, NASA TN D-5612 (1970).

[15] Y. Ma, J.N. Chung, A study of bubble dynamics in reduced gravity forced-convection boiling, Int J. Heat Mass Transf 44 (2001) 399-415.

[16] D. Serret, D. Brutin, O. Rahli, L. Tadrist, Convective boiling between 2D plates: microgravity influence on bubble growth and detachment, Microgravity Sci. Technol. 22 (2010) 377-385.

[17] H. Ohta, Experiments on microgravity boiling heat transfer by using transparent heaters, Nucl. Eng. Des. 175 (1997) 167-180.

[18] G.P. Celata, M. Cumo, M. Gervasi, G. Zummo, Flow pattern analysis of flow boiling in microgravity, Microgravity Sci. Technol. 19 (2) (2007) 183-210.

[19] O. Kawanami, H. Azuma, H. Ohta, Effect of gravity on cryogenic boiling heat transfer during tube quenching, Int. J. Heat Mass Transf. 50 (17-18) (2007)
3490-3497.

[20] G.P. Celata, M. Cumo, M. Gervasi, G. Zummo, Quenching experiments inside 6.0 mm tube at reduced gravity, Int. J. Heat Mass Transf. 52 (11) (2009) 2807-2814.

[21] C. Baltis, G.P. Celata, M. Cumo, L. Saraceno, G. Zummo, Gravity influence on heat transfer rate in flow boiling, Microgravity Sci. Technol. 24 (3) (2012) 203-213.

[22] M. Narcy, E.D. Malmazet, C. Colin, Flow boiling in tube under normal gravity and microgravity conditions, Int. J. Multiphase Flow 60 (2) (2014) 50-63.

[23] Y. Ma, J.N. Chung, An experimental study of critical heat flux (CHF) in microgravity forced-convection boiling, Int. J. Multiphase Flow 27 (2001) 1753-1767.

[24] H. Zhang, I. Mudawar, M.M. Hasan, Flow boiling CHF in microgravity, Int. J. Heat Mass Transf. 48 (15) (2005) 3107-3118.

[25] C. Konishi, H. Lee, I. Mudawar, M.M. Hasan, H.K. Nahra, N.R. Hall, J.D. Wagner, R.L. May, J.R. Mackey, Flow boiling in microgravity: Part 1 - Interfacial behavior and experimental heat transfer results, Int. J. Heat Mass Transf. 81 (2015) 705-720.

[26] C. Konishi, H. Lee, I. Mudawar, M.M. Hasan, H.K. Nahra, N.R. Hall, J.D. Wagner, R.L. May, J.R. Mackey, Flow boiling in microgravity: Part 2 - Critical heat flux interfacial behavior, experimental data, and model, Int. J. Heat Mass Transf. 81 (2015) 721-736.

[27] Y.H. Zhang, B. Liu, J.F. Zhao, Y.P. Deng, J.J. Wei, Experimental study of subcooled flow boiling heat transfer on a smooth surface in short-term microgravity, Microgravity Sci. Technol. 30 (6) (2018) 793-805.

[28] Y.H. Zhang, B. Liu, J.F. Zhao, Y.P. Deng, J.J. Wei, Experimental study of subcooled flow boiling heat transfer on micro-pin-finned surfaces in short-term microgravity, Exp. Therm. Fluid Sci. 97 (2018) 417-430.

[29] B. Liu, B. Yuan, P.Z. Xu, J.F. Zhao, Y.H. Zhang, J.J. Wei, Y. Yang, Q. Cao, A method for approximating the CHF of subcooled flow boiling in microgravity by ground tests, Int. J. Multiphase Flow 122 (2020) 103161.

[30] X.Q. Zhang, L.G. Yuan, W.D. Wu, L.Q. Tian, K.Z. Yao, Some key technics of drop tower experiment device of National Microgravity Laboratory (China) (NMLC), Sci. China, Ser. E: Eng. Mater. Sci. 48 (3) (2005) 305-316.

[31] K.N. Rainey, S.M. You, S. Lee, Effect of pressure, subcooling, and dissolved gas on pool boiling heat transfer from microporous, square pin-finned surfaces in FC-72, Int. J. Heat Mass Transf. 46 (1) (2003) 23-35.

[32] H. Honda, H. Takamastu, J.J. Wei, Enhanced boiling of FC-72 on silicon chips with micro-pin-fins and submicron-scale roughness, ASME. J. Heat Transfer 124 (2) (2002) 383-390.

[33] D.M. Iceri, G. Zummo, L. Saraceno, G. Ribatski, Convective boiling heat transfer under microgravity and hypergravity conditions, Int. J. Heat Mass Transf. 153 (2020) 119614.

[34] H. Zhang, I. Mudawar, M.M. Hasan, Application of flow boiling for thermal management of electronics in microgravity and reduced-gravity space systems, IEEE Trans. Compon. Packag. Technol. 32 (2) (2009) 466-477.

[35] M. Kureta, H. Akimoto, Critical heat flux correlation for subcooled boiling flow in narrow channels, Int. J. Heat Mass Transf. 45 (20) (2002) 4107-4115. 